\title{
CFD Modeling of Multiphase Flow in an SKS Furnace with New Tuyere Arrangements
}

\begin{abstract}
KEZHOU SONG and ARI JOKILAAKSO
There has been a great deal of focus on the optimization of tuyere arrangements in SKS bottom blown copper smelting furnaces since the last decade, as the improved furnace operation efficiency of SKS technology has potential that cannot be ignored. New $-x+0+x$ deg tuyere arrangements with 14 tuyeres are proposed in this research paper. Using a previously verified numerical model, CFD tests on the velocity distribution and wall shear stress for scaled-down SKS furnace models were conducted, with a constant total volumetric gas flow rate, and different operating parameters and furnace cross-section geometries. The results indicate that, at a relatively low gas injection speed compared with the previously optimized tuyere arrangement, although the $-x+0+x$ deg tuyere arrangements are unable to supply enhanced agitation in the typical round furnaces, they achieve better performance in elliptical furnaces. At a comparatively higher gas injection speed, the $-x+0+x$ deg tuyere arrangements can improve the agitation performance in a round furnace while maintaining an acceptable wall shear stress on the bottom and side wall. The agitation enhancement with the $-x+0+x$ deg tuyere arrangements can essentially be attributed to stronger interactions between bubble plumes and furnace side walls. To further exploit the advantages of the new tuyere arrangements, an optimized tuyere angle was confirmed by a full-scale furnace model simulation.
\end{abstract}

https://doi.org/10.1007/s11663-021-02362-9

(c) The Author(s) 2021

\section{INTRODUCTION}

COPPER production technologies have been continuously optimized and updated, due to the large demand from the global copper market. ${ }^{[1]}$ The world consumption of refined copper has witnessed a growing trend for over a hundred years since the beginning of the last century. ${ }^{[2]}$ Such a growing market and changing raw materials (lower grade ores) have given rise to new developments in furnaces and supporting facilities. Alongside the use of flash smelting technology, which accounts for over half of the total copper production capacity, ${ }^{[2]}$ new bath smelting technologies have also been developed and promoted. The bottom blown copper smelting process, referred to as SKS (Shui Kou Shan) technology, has attracted growing interest since the last decade, due to its good, productive, and environmental performance. ${ }^{[3]}$ Moreover, as a bath smelting furnace, the SKS furnace is more suitable for secondary (scrap) raw materials than flash smelting

KEZHOU SONG and ARI JOKILAAKSO are with the Department of Chemical and Metallurgical Engineering, School of Chemical Engineering, Aalto University, P.O. Box 16100, Kemistintie 1, 02150 Espoo, Finland. Contact e-mail: ari.jokilaakso@aalto.fi

Manuscript submitted August 16, 2021; accepted October 21, 2021.

Article published online December 27, 2021. furnaces and, therefore, could be an effective approach for metal waste recycling. In light of the increasing amount of e-wastes to be treated, ${ }^{[4]}$ the use of SKS technology is a promising way to meet wider requirements, not only for finely ground copper concentrates from traditional mining processes, but also for waste electronic copper bearing scrap, such as WPCB (waste printed circuit boards). ${ }^{[5]}$

In 2019, SKS technology accounted for only 4 pct of the global copper smelter production capacity, ${ }^{[6]}$ but it has rapidly been adopted in the Asian copper making industry in the last 10 years. ${ }^{[7]}$ The SKS bottom blown copper smelting furnace has a horizontal cylinder structure. Oxygen enriched air is injected at high speed via tuyeres installed at the bottom of the furnace, producing a strong agitation in the matte phase, thus achieving high mixing and thermal efficiency. Different optimization methods regarding the furnace structure have been proposed, mainly aimed at better mixing efficiency through new tuyere arrangements and other adjustable parameters. For example, ENFI arranged 14 tuyeres in one line at the furnace bottom with each pair of tuyeres being close to each other. Usually, only some of these tuyeres were in use, depending on the actual demand in certain circumstances. ${ }^{[8]}$ The one-line tuyere arrangement was also practiced at Hengbang, whose furnace had only six tuyeres. ${ }^{[9]}$ However, with this design it proved to be hard to reduce the copper loss in 
the slag phase and was discontinued. Another case is that of Fangyuan, where an arrangement of nine tuyeres arranged in two lines with different angles was successfully tested with good production performance. ${ }^{[10]}$

Changes in tuyere arrangements have a significant effect on the agitation behavior in furnaces and therefore deserve further investigation. As an emerging technology exploited firstly by copper producers, the improvement of SKS furnaces has mainly originated from industrial operational experience, which is a costly way to carry out trials with different parameters. Strong theoretical support from modeling work is necessary to make the basis for tuyere arrangements and furnace structure modification more scientific. For this purpose, research on a scaled-down water model of an SKS furnace was conducted by Shui et al. from 2015 to 2018, targeting the modeling of wave behavior at different tuyere angles. ${ }^{[11,12]}$ Simultaneously, a single tuyere water model test on the SKS furnace flow field was completed by Wang et al., ${ }^{[13]}$ in which the velocity distribution under different conditions was revealed by the usage of PIV technology. Water model research provides good references for furnace optimization and can also provide an efficient comparison when combined with computational fluid dynamics (CFD) simulation. Various numerical models have been applied to SKS furnace multiphase flow simulation. The volume of fraction (VOF) model, capable of tracking the interface of a multiphase flow, was applied in the simulation of SKS furnaces by Yan et al. and Dong et al. ${ }^{[14,15]}$ The performance of the VOF model has been partially verified by observation of the bubble or plume shapes, without an integral test on the agitation or mixing behavior in the whole agitation zone. According to these studies, a tuyere angle over $17 \mathrm{deg}$ is suggested for better mixing behavior. Another CFD study based on a scaled-down SKS furnace model was conducted by Shao et al. ${ }^{[16]}$ using the Eulerian model, in which the mixing efficiency under different conditions was reported. According to Shao et al. a combination of tuyere angles of 7 and 14 deg for two lines of tuyeres is recommended for higher gas holdup in the bath. However, this conclusion cannot be used directly because a key parameter, i.e., the simulated tuyere diameter, is not reported by the authors. As a simple review, the CFD studies related to tuyere arrangements in SKS furnaces are listed in Table I.

CFD studies on some of the SKS furnace resembled furnaces would provide useful information on the SKS furnace investigations. The literature on copper bath smelting and converting vessel modeling studies has been recently reviewed. ${ }^{[1]}$ The flow field of the side blown regime has common features with that of the bottom blown regime in SKS furnaces. In the last decade, CFD simulation research on side blown metallurgical furnaces has been conducted mainly regarding Peirce-Smith (PS) converters ${ }^{[18,19]}$ and Vanyukov furnaces. ${ }^{[20]}$ The VOF model was mostly used in these reported studies, and the basic flow fields presented. ${ }^{[18-20]}$ The DPM model adopted in work on ladle modeling $^{[21]}$ has not yet been implemented in the modeling of copper smelting or converting furnaces.
This is possibly because of very different flow fields of ladle and smelting/converting furnaces. The gas injection speed for SKS furnaces is even more radical than those for other bath smelting or converting furnaces, almost transforming the bubbly flow into a jetting flow. To establish a feasible way to describe the flow field in the SKS furnace, the numerical models used for other furnaces were tested by different research groups, as listed in Table I.

The SKS furnace modeling studies reported by different work groups used different furnace structure parameters, modeling methods, and numerical setups, hence some conflicts appeared in the optimization results. Regarding both the reliability and adaptation of the modeling results, the furnace parameters selected were in a very common range and a new numerical method using the Multifluid VOF model was verified in our previous SKS furnace CFD modeling study (shown in Table I). ${ }^{[17]}$ The simulated results were not only in good agreement with the bubble plume shape, but also with the wave frequency and amplitude from the reported water model research. ${ }^{[12]}$ Using the verified numerical model, the velocity distribution and wall shear stress at different tuyere arrangements were investigated. It was found that tuyeres arranged on both sides contributed to a reduction in the size of the low velocity area and dead zone in the agitation area. It was suggested that the angle difference of the two-line tuyeres should be at a comparatively higher level, to avoid impact overlapping on the bottom wall. The results from our previous study provided key references for the new CFD research reported in this work, in which new tuyere arrangements and an elliptical furnace cross-section for SKS technology were proposed and tested. The main objective of this study is to further explore the potential of the SKS furnace by providing new insights into gas plume behavior and agitation of the bath by the new tuyere arrangements under different conditions, and finally by suggesting new options for the optimization of industrial furnace geometry and operation.

\section{MATHEMATICAL MODEL}

The performance of the numerical model adopted in this simulation was verified in our previous CFD study. ${ }^{[17]}$ According to the comparison, the simulated water model highly resembles the reported experimental water model, in terms of both the plume shape and the characteristics of the surface waves, indicating the construction of a very similar flow field. ${ }^{[17]}$ Therefore, the parameters of the previous numerical model were maintained in this work. The description of the math is as follows.

\section{A. Governing Equations}

The mass and momentum conservation equations for phase $q$ (including the gas phase and liquid phase) are given as Eqs. [1] and [2], ${ }^{[17]}$ respectively. 


$$
\begin{gathered}
\frac{\partial}{\partial t}\left(\alpha_{q} \rho_{q}\right)+\nabla \cdot\left(\alpha_{q} \rho_{q} \vec{v}_{q}\right)=0 \\
\frac{\partial}{\partial t}\left(\alpha_{q} \rho_{q} \vec{v}_{q}\right)+\nabla \cdot\left(\alpha_{q} \rho_{q} \vec{v}_{q} \vec{v}_{q}\right) \\
=-\nabla p+\nabla \cdot\left[\mu\left(\nabla \vec{v}_{q}+\nabla \vec{v}_{q}^{T}\right)\right]+\alpha_{q} \rho_{q} \vec{g}+\vec{f} \\
\alpha_{q}=\alpha_{g} \text { or } \alpha_{l}, \alpha_{g}+\alpha_{l}=1
\end{gathered}
$$

In Eqs. [1] through [3], $\alpha$ is the volume fraction, $\rho$ is the density, $\vec{v}$ is the velocity, $\mathrm{p}$ is the pressure shared by both two phases, $\alpha_{q} \rho_{q} \vec{g}$ is the gravity term, and $\vec{f}$ is an external body force which is specifically defined as the drag force in the current system. The subscripts $g$ and $l$ represent the gas and liquid phases, respectively.

\section{B. Drag Force}

Some of the interphase forces, such as the turbulence dispersion force, may influence the plume shape to some extent when the injection speed is in a comparatively low range. ${ }^{[17]}$ However, in the present simulation, there is a very high gas injection speed that is far beyond the reported range, ${ }^{[17]}$ so the drag force is a factor that cannot be ignored, and requires study. As detailed bubble behavior is not the main focus of this work, other interphase forces were ignored to improve the calculation efficiency, with the exception of the drag force. Drag force is introduced based on the symmetric model provided by the Multi-Fluid VOF model. ${ }^{[22]}$ For the symmetric model, the density and viscosity are calculated from volume averaged properties:

$$
\begin{aligned}
& \rho_{\mathrm{gl}}=\alpha_{\mathrm{g}} \rho_{\mathrm{g}}+\alpha_{1} \rho_{1} \\
& \mu_{\mathrm{g} l}=\alpha_{\mathrm{g}} \mu_{\mathrm{g}}+\alpha_{1} \mu_{1}
\end{aligned}
$$

and the diameter of bubbles or droplets is defined as

$$
d_{\mathrm{gl}}=\frac{1}{2}\left(d_{\mathrm{g}}+d_{1}\right)
$$

In turn, the drag function could be given as

$$
f=\frac{C_{D} R e}{24}
$$

where the relative Reynold number $R e$ is

$$
R e=\frac{\rho_{\mathrm{gl}}\left|\vec{v}_{\mathrm{g}}-\vec{v}_{1}\right| d_{\mathrm{gl}}}{\mu_{\mathrm{gl}}}
$$

and the drag coefficient $C_{D}$ is

$$
C_{D}=\left\{\begin{array}{c}
24\left(1+0.15 R e^{0.687}\right) / R e \quad R e \leq 1000 \\
0.44 \quad \operatorname{Re} \geq 1000
\end{array}\right.
$$

The drag force is only affected by the bubble or droplet diameter, since values of the other variables are all taken from industrial data. In this simulation, compared to the common situation in other copper making processes with bubbly flow regimes, ${ }^{[18-21]}$ the gas injection speed is very high, transforming the bubbly 

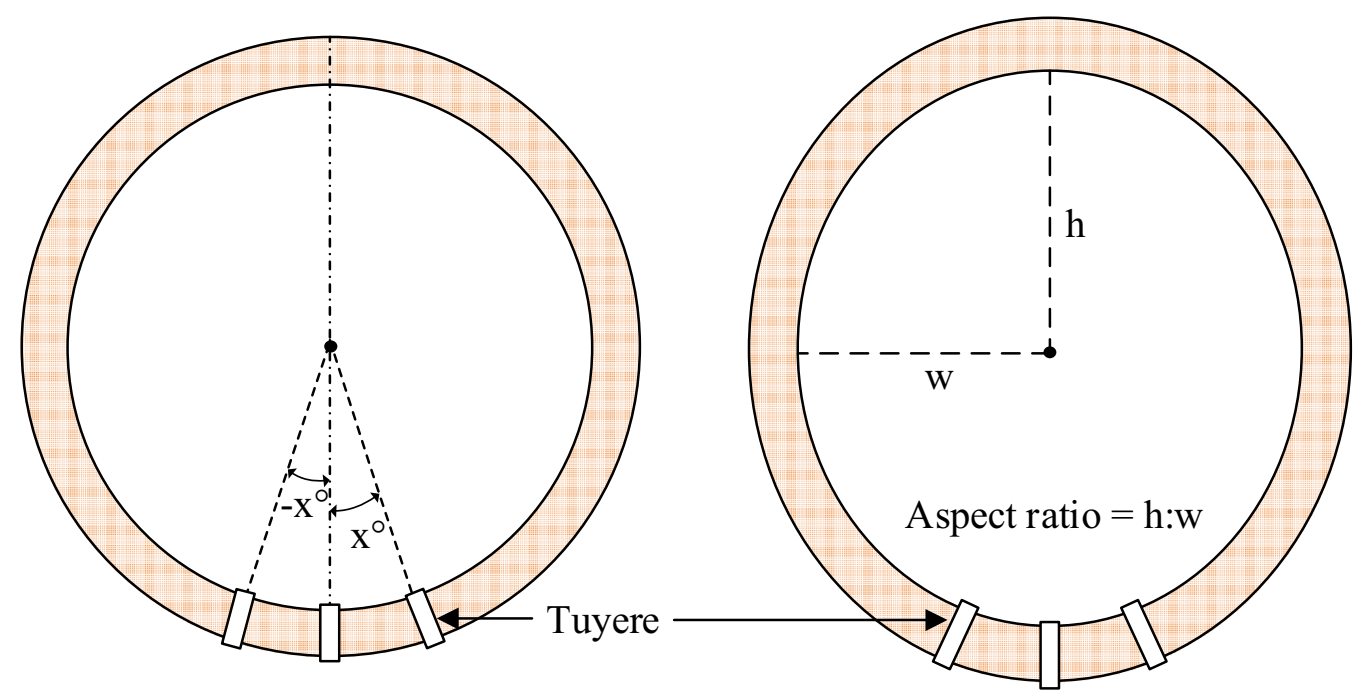

Fig. 1-A schematic diagram of the tuyere angle and aspect ratio definition. The positive and negative values of the tuyere angle correspond to tuyeres installed on different sides of the simulated SKS furnace.

flow into an almost jetting flow. The bubbles aggregate into a bubble group or bigger bubbles of irregular shape, based on experimental photographs from Shui et al. ${ }^{[2]}$. This makes the bubble diameter vary a lot and makes it difficult to evaluate. Therefore, as the bubbles tend to aggregate and probably coalesce, consideration is given primarily to the continuity of the bubble plume. As proposed earlier ${ }^{[17]}$ the bubble plume is regarded as a bubble ribbon. This enables the gas phase to be set as a continuous phase and hence the droplet diameter is defined instead. The diameter value was determined based on whether the plume shape (or ribbon shape) agreed with the experimental images, ${ }^{[12]}$ and finally the default value of $0.00001 \mathrm{~m}$ was adopted.

\section{Turbulence Models}

The standard $k-\varepsilon$ turbulence model with standard wall functions is adopted for the present simulation. The kinetic energy $k$ and its rate of dissipation $\varepsilon$ yields are as follows:

$$
\begin{aligned}
\frac{\partial}{\partial t}\left(\rho_{\mathrm{m}} k\right)+\nabla \cdot\left(\rho_{\mathrm{m}} \vec{v}_{\mathrm{m}} k\right)= & \nabla \cdot\left(\alpha_{1} \frac{\mu_{t}}{\sigma_{k}} \nabla k\right)+G_{k} \\
& +G_{\mathrm{b}}-\rho_{\mathrm{m}} \varepsilon \\
\frac{\partial}{\partial t}\left(\rho_{\mathrm{m}} \varepsilon\right)+\nabla \cdot\left(\rho_{\mathrm{m}} \vec{v}_{\mathrm{m}} \varepsilon\right)= & \nabla \cdot\left(\frac{\mu_{t}}{\sigma_{k}} \nabla \varepsilon\right) \\
& +\frac{\varepsilon}{k}\left(C_{1 \varepsilon}\left(G_{\mathrm{k}}+G_{\mathrm{b}}\right)\right) \\
& -C_{2 \varepsilon} \rho_{\mathrm{m}} \varepsilon
\end{aligned}
$$

where $G_{\mathrm{k}}$ represents the generation of turbulence energy due to the mean velocity gradients, and $G_{\mathrm{b}}$ is the turbulence energy due to buoyancy. The mixture density $\rho_{\mathrm{m}}$ and mixture velocity $\vec{v}_{\mathrm{m}}$ are defined as follows:

$$
\rho_{\mathrm{m}}=\alpha_{\mathrm{g}} \rho_{\mathrm{g}}+\alpha_{\mathrm{l}} \rho_{1}
$$

$$
\vec{v}_{\mathrm{m}}=\frac{\alpha_{\mathrm{g}} \rho_{\mathrm{g}} \vec{v}_{\mathrm{g}}+\alpha_{1} \rho_{\mathrm{l}} \vec{v}_{\mathrm{l}}}{\alpha_{\mathrm{g}} \rho_{\mathrm{g}}+\alpha_{1} \rho_{1}}
$$

The empirical constants are $C_{1 \varepsilon}=1.44, C_{2 \varepsilon}=1.92$, $\sigma_{k}=1, \sigma_{k}=1.3$. The turbulence viscosity $\mu_{t}$ is given as Eq. [14].

$$
\mu_{t}=\rho_{\mathrm{m}} C_{\mu} \frac{k^{2}}{\varepsilon}, C_{\mu}=0.09
$$

\section{GEOMETRY AND SIMULATION CONDITIONS}

\section{A. Physical Model}

\section{New tuyere arrangements}

Traditionally, the tuyeres in an SKS furnace are installed on only one side, to avoid splashing droplets going into the feed inlet and to make tuyere replacement more convenient. However, as the agitation behavior could be significantly strengthened by having tuyeres installed on both sides, ${ }^{[17]}$ further investigation and optimization were felt to be necessary. In this simulation, new tuyere arrangements were proposed and tested in both round and elliptical furnace sections. To describe the new tuyere arrangements and the geometry of elliptical furnace sections clearly and quantitatively, the tuyere angle and the aspect ratio of elliptical sections are depicted in Figure 1. Hereinafter, furnaces with round and elliptical furnace cross-sections are abbreviated as "round furnace" and "elliptical furnace". 


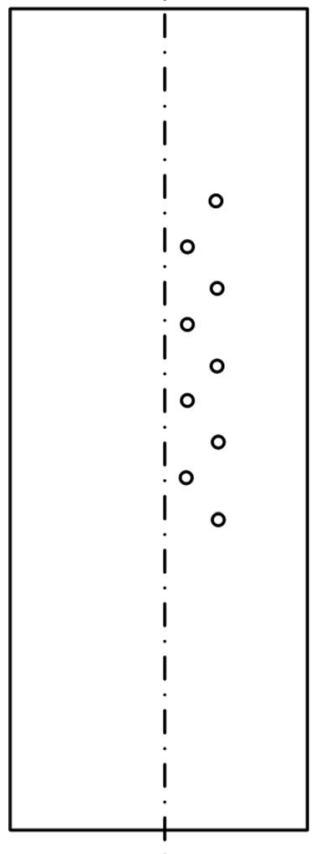

Original

$7+22$ degrees

(a)

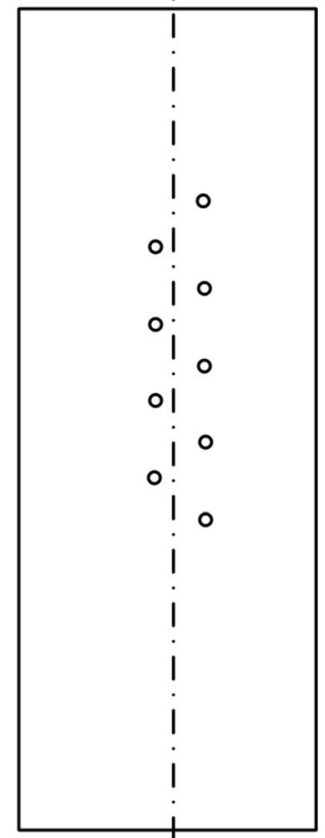

Suggested from previous work $-7+14$ degrees

(b)

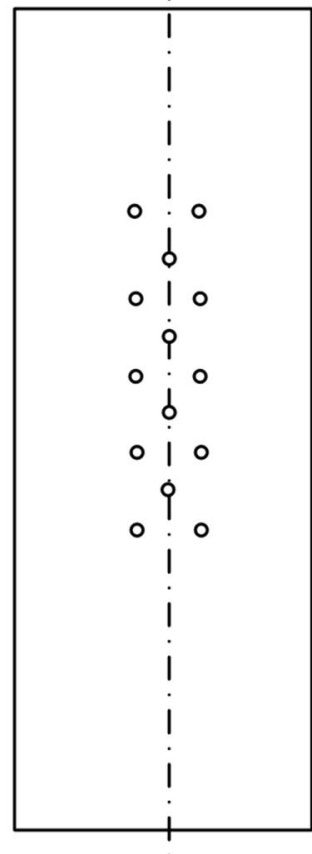

New arrangement $-\mathrm{x}+0+\mathrm{x}$ degrees

(c)

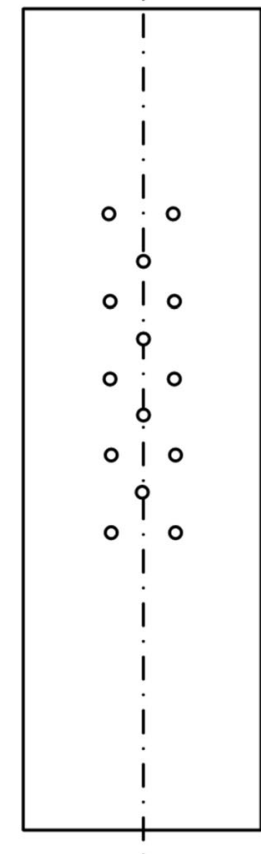

New arrangement in elliptical furnace $-\mathrm{x}+0+\mathrm{x}$ degrees

(d)

Fig. 2-Previous and new tuyere layouts. (a) Original Fangyuan tuyere arrangement; (b) Optimized tuyere arrangement from our previous study ${ }^{[17]} ;(c)$ New tuyere arrangement; $(d)$ New tuyere arrangement in elliptical furnace.

The proposed new tuyere arrangements, referred to as $-x+0+x$ deg, where the number of tuyeres has been increased to 14, are shown in Figure 2. Four tuyeres are installed along the bottom middle line with five tuyeres installed symmetrically on each side of the furnace, as the symmetry of the tuyeres contributes to increasing the mechanical stability of the furnace body. The tested tuyere angles were selected based on the following points, according to our previous CFD study: ${ }^{[17]}$

(1) Tuyeres arranged on both sides contribute to reducing the low velocity area.

(2) The distance between adjacent tuyeres should be set within a certain range to balance the requirement of better agitation efficiency and longer refractory life span.

The new tuyere arrangements were also tentatively tested in an elliptical furnace body, given the following assumptions:

(1) The near wall low velocity area could be reduced.

(2) The injected enriched oxygen has a longer floating trajectory below bath level.

(3) A smaller contact area between matte and slag phases would help phase separation.

\section{Parameters of the simulated SKS furnace model}

In this work, the total volumetric gas flow rate and pool depth are fixed. The tuyere diameter is adjustable but is determined depending on the gas injection speed to keep the total volumetric gas flow rate constant. Comparatively higher values were chosen for gas flow rate and pool depth to make the results closer to the expected situation in industry, as these parameters tend to be improved to achieve a higher production capacity. Different tuyere angles and furnace section aspect ratios were investigated to obtain an optimized parameter combination.

In this work, simulated scaled-down SKS furnace models were created for a prototype at a ratio of 1:12, with new tuyere arrangements and an elliptical furnace body instead of a round one. The simulated full-scale model was at a ratio of 1:1 to the prototype, and the tuyere arrangements were chosen from the optimization results from the scaled-down model simulation. The relative parameters are shown in Table II. The volumetric gas flow rate was calculated based on the modified Froude number Fr', which is given as Eq. [15]:

$$
\mathrm{Fr}_{\mathrm{m}}^{\prime}=\frac{\rho_{\mathrm{gm}} u_{\mathrm{m}}^{2}}{\left(\rho_{\mathrm{lm}}-\rho_{\mathrm{g}}\right) g L_{\mathrm{m}}}=\frac{\rho_{\mathrm{gp}} u_{\mathrm{p}}^{2}}{\left(\rho_{\mathrm{lg}}-\rho_{\mathrm{gp}}\right) g L_{\mathrm{p}}}=\mathrm{Fr}_{\mathrm{p}}^{\prime}
$$

where subscript $m$ represents the simulated SKS furnace model, subscript $p$ represents the prototype, $u$ is the volumetric gas flow rate, and $L$ is the characteristic length.

To improve the calculation efficiency, the following simplifications have been implemented in the physical model:

(1) The furnace structure is simplified as a simple cylinder. 


\begin{tabular}{|c|c|c|c|c|c|}
\hline & \multirow[b]{2}{*}{ Prototype ${ }^{[10,13]}$} & \multirow{2}{*}{$\begin{array}{l}\text { Previously } \\
\text { Optimized } \\
\text { Model }^{[17]}\end{array}$} & \multicolumn{2}{|c|}{$-x+0+x \underset{\text { deg Tuyere Arrange- }}{\text { ments }}$} & \multirow{2}{*}{$\begin{array}{l}\text { Full-Scale } \\
\text { Model }\end{array}$} \\
\hline & & & Round & Elliptical & \\
\hline Inner Diameter [mm] & 3490 & 290 & 290 & 290 & 3490 \\
\hline Length $[\mathrm{mm}]$ & 15084 & 1250 & 1250 & 1250 & 15000 \\
\hline Number of Operational Tuyeres & 9 & 9 & 14 & 14 & 14 \\
\hline Tuyere Diameter [mm] & 60 & 5 & 4,5 & 5 & 48 \\
\hline Tuyere Angle & $7+22 \mathrm{deg}$ & $7+14 \mathrm{deg}$ & $\begin{array}{c}x+0+x \operatorname{deg} \\
x=14,16,18\end{array}$ & $\begin{array}{l}x+0+x \text { deg } \\
x=14,16,18\end{array}$ & $16+0+16 \mathrm{deg}$ \\
\hline Depth of Liquid [mm] & 1200 to 1800 & 120 & 120 & 120 & 1440 \\
\hline Gas Flow Rate $\left[\mathrm{m}^{3} \mathrm{~h}^{-1}\right]$ & 5000 to 15000 (in total) & 23.4 (in total) & 23.4 (in total) & 23.4 (in total) & 11700 (in total) \\
\hline Gas/Gas Density $\left[\mathrm{kg} \mathrm{m}^{-3}\right]$ & enriched oxygen $/ 1.38$ & air $/ 1.38$ & air $/ 1.38$ & air $/ 1.38$ & air $/ 1.38$ \\
\hline Matte Density $\left[\mathrm{kg} \mathrm{m}^{-3}\right]$ & 4440 & 4440 & 4440 & 4440 & 4440 \\
\hline Matte Viscosity [Pa s] & 0.004 & 0.004 & 0.004 & 0.004 & 0.004 \\
\hline Matte Interface Tension $\left[\mathrm{N} \mathrm{m}^{-3}\right]$ & 0.33 & 0.33 & 0.33 & 0.33 & 0.33 \\
\hline
\end{tabular}

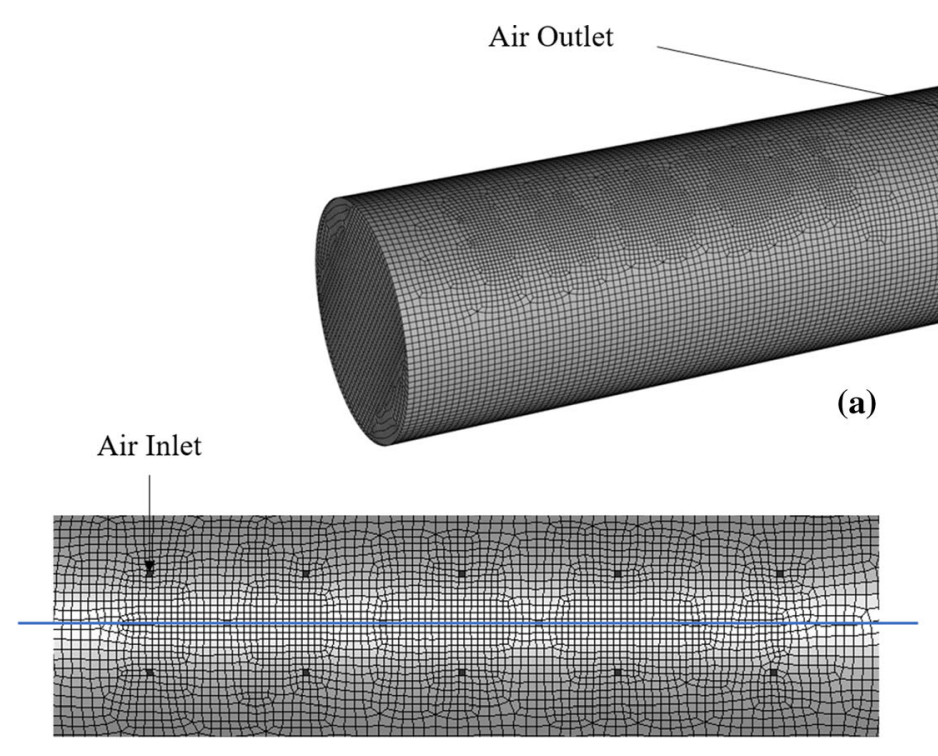

(b)

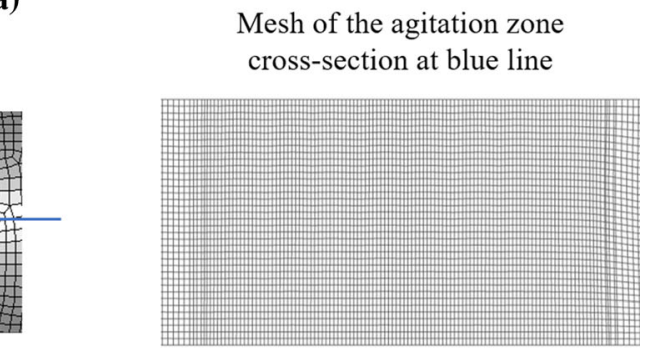

(c)

Fig. 3- (a) Mesh of the simulated SKS furnace. (b) Mesh arrangement of the tuyere area. Cells in full black are the inlets where tuyeres are located. (c) Mesh of the agitation zone cross-section marked with a blue line from (b) (Color figure online).

(2) There is no heat and mass transfer in the physical model. This would not have a major influence on the simulation accuracy as the key parameters of high-temperature matte and oxygen enrichment remain.

(3) There is no slag phase present in the water model as a small amount of slag is not able to affect the bubble plume significantly. Also, the results in the current work should be regarded as a simulation of an initial operating stage in an SKS furnace.
On the other hand, a thick slag layer would influence the flow field, and this will be investigated in the future. However, in SKS furnaces, strong agitation at the bath surface leads to a very different situation compared with gas stirring in ladles where, e.g., the slag eye is an important point to examine. In the present study, as an exploration work of new tuyere arrangements, the primary focus is on basic tests without the slag phase. 


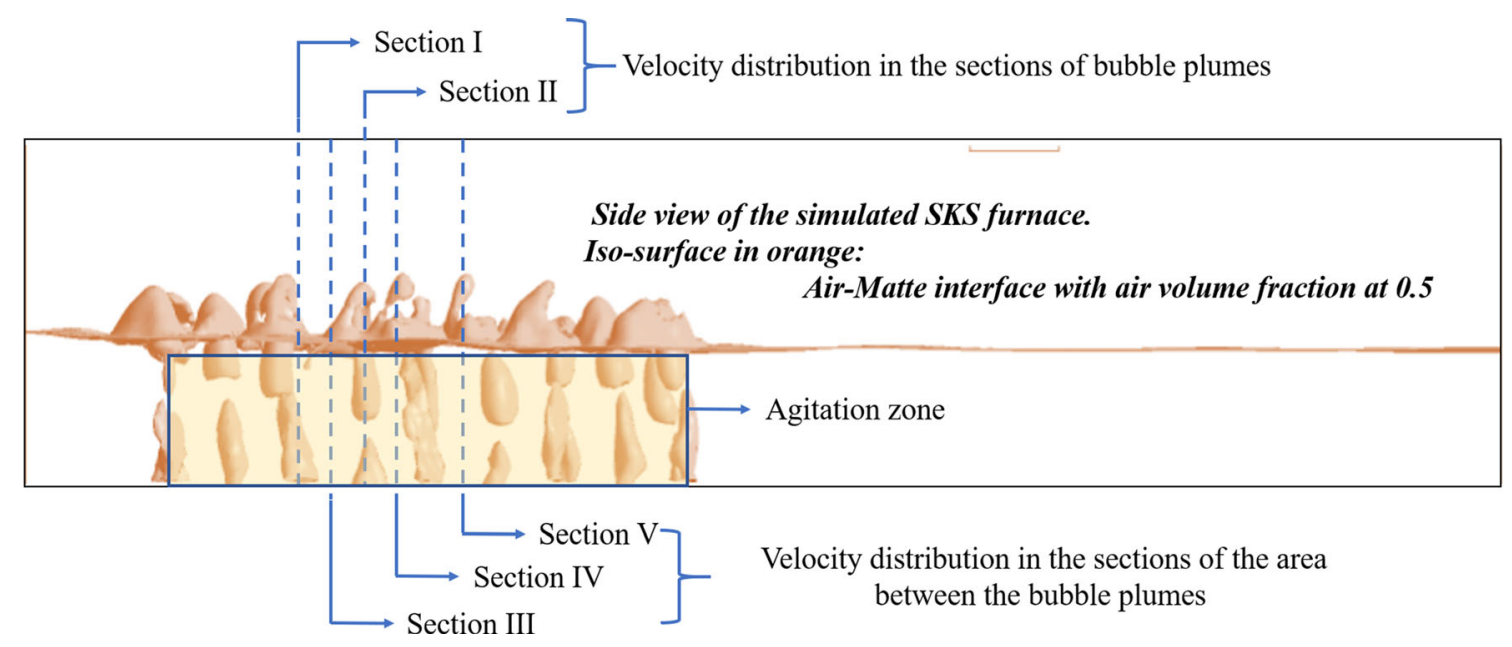

Fig. 4 - Side view of the simulated SKS furnace. The iso-surface, shown in orange, is the air-matte interface with an air volume fraction of 0.5 (Color figure online).

\section{B. CFD Modeling}

\section{CFD setup}

The mesh of the simulated SKS furnace is shown in Figure 3. In each case, multizone meshing was adopted with hexahedral mesh as the majority. Similarly to the previous work, the gas inlets of very small size (less than $1 / 58$ of the furnace section diameter) were simplified and made square to improve the mesh quality and calculation efficiency. To verify that the macroscopic flow field was independent of the mesh size and inlet mesh simplification, especially the low velocity regions and wall shear stress analyzed in this simulation, a preliminary mesh test was completed which can be seen in the appendix of our previous study. ${ }^{[17]}$ The number of cells with the current meshing setup was eventually set within the range of 280,000-300,000. For each mesh of cases with different tuyere arrangements and furnace cross-section geometries, more than 99.69 pct of the elements are of a skewness below 0.5 , which translates into good or excellent cell quality. The others, less than 0.31 pct, are of a skewness below 0.6, evaluated as fair cell quality. ${ }^{[23]}$

The gas inlets are located at the furnace bottom and set as the velocity inlet. The gas outlet is located at the top surface at a distance from the agitation zone and was set as the pressure outlet. For better balanced calculation speed and result accuracy, the time-step was set as $5 \times 10^{-4}$ seconds, and the convergence marked by a dimensionless residual of less than $1 \times 10^{-3}$. All control equations in this simulation were calculated using the commercial software Ansys Fluent 2019 R3.

\section{Verification of the numeric model}

In this work, the previously reported model size, gas blowing method, and similar operating parameters ${ }^{17]}$ have been adopted. Therefore, the numerical setup from the previous work has not been changed, and the current numerical scheme has already been verified by a comparison with water model tests reported by Shui et al.$^{[12]}$ Preliminary geometrical test results showed that the simulated water models and scaled-down SKS furnaces closely resemble the reported water models in terms of the position and the shape of the bubble plumes, and even the type of surface waves. A wave test was then conducted to further observe the similarities between the CFD and water models. The dimensionless wave frequency of the simulated water model was found to be 1.495 , which is very close to the reported 1.566 of the corresponding water model experiment. The wave amplitude was also in the reported range derived from the reported water model test results in very similar conditions. As the surface waves with certain frequency and amplitude only form at a certain range of gas injection speed and bath depth, the wave verification results indicated that a highly similar flow field was macroscopically constructed. The related detailed verification processes and figures can be seen in our previous work. $^{[17]}$

\section{RESULTS AND DISCUSSION}

The new tuyere arrangements are evaluated by comparison with the previous optimized case in the performance of velocity distribution and wall shear stress. In this work, the velocity distribution is displayed at selected sections of the simulated furnace model, as shown in Figure 4. To compare with the optimized case from the previous study, these sections are identically taken from the middle of the agitation zone, which was also selected in the previous study to involve the interactions between adjacent gas plumes. In addition, the agitation zone is also marked in Figure 4, in which the volume fraction of the dead zone has been calculated to evaluate the agitation performance. The dead zone for scaled-down SKS furnace baths is defined as the region with a matte velocity of less than $0.05 \mathrm{~m} \mathrm{~s}^{-1}$.

Reducing the dead zone and low velocity regions could be an efficient way to optimize the agitation performance and oxygen diffusion. For a relatively long-term observation of the low velocity areas, the quietest points were chosen from the gas plume sections 


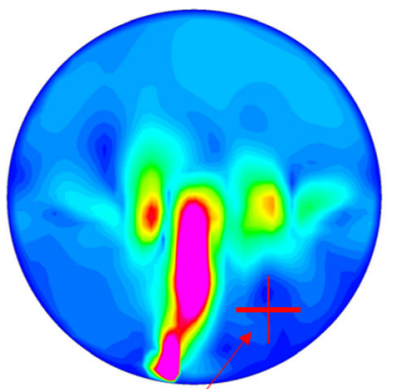

Point $1 *$

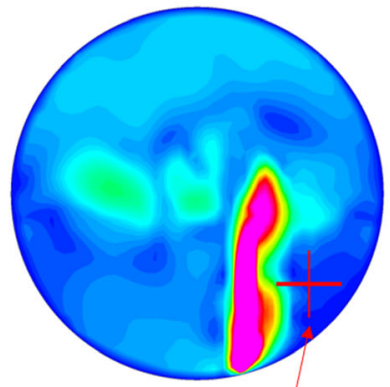

Point 2*
Tuyere angle: $-7^{\circ}+14^{\circ}$ (previously optimized)

(a)

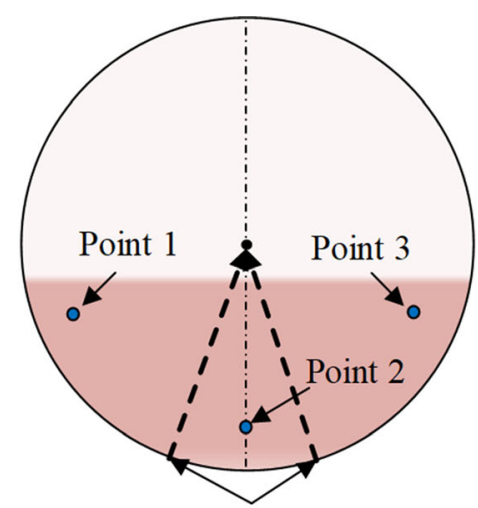

Gas injecting direction
New arrangements

(b)

Fig. 5- Quietest points for the observation of velocity variation. (a) Low velocity points in the previously optimized case ${ }^{[17]}$; $(b)$ low velocity points in the cases of the current simulation with new tuyere arrangements.

in the case of tuyere angles $-7+14 \mathrm{deg}$, which gave the best performance in the previous simulation, ${ }^{[17]}$ and the double plume sections from the case of the new tuyere arrangements in the current simulation. The positions of the selected points are shown in Figure 5, where Point $1 *$ and Point $2^{*}$ are the low-speed areas chosen from the previously optimized case. For the case of the new tuyere arrangements, comparatively low velocity regions or dead zones mostly appear in the double tuyere sections, with three regions always in a quiet situation. These areas can be observed at Points 1 to 3 in Figure 5(b). The velocity variation for Point $1 *, 2 *$, and Points 1 to 3 was recorded from 2 to 10 seconds.

\section{A. Simulated Scaled-Down SKS Model with $-x+0+x$ deg Tuyere Arrangements}

In this subchapter, the CFD simulation results are discussed regarding the new tuyere arrangements in the scaled-down physical models with different tuyere angles and elliptical section aspect ratios. The total gas volume velocities were identical for all of the analyzed cases. The tuyere diameter and the gas injection speed were changed to maintain a constant total volumetric gas flow rate. The gas injection speed of $36.80 \mathrm{~m} \mathrm{~s}^{-1}$ and tuyere diameter of $5 \mathrm{~mm}$, which were set for the previously optimized case with tuyere angles of $-7+14 \mathrm{deg}$, were regarded as the original parameters, and the testing conditions were changed based on these original values. This means that when adopting the tuyere diameter of $5 \mathrm{~mm}$ of the original model, the gas injection speed had to be reduced to $23.67 \mathrm{~m} \mathrm{~s}^{-1}$, because the total number of tuyeres had been increased from the original nine to the current 14 for the $-x+0+x$ deg tuyere arrangements.

Due to the high gas injection speed, in the initial period the bubbles broke the bath surface within a short time, thus forming a circulation zone beneath the bath level before approximately 2 seconds. This enabled a relatively steady flow field including plume zone, fountain zone, circulation zone, and dead zone, can then be observed. It was found that a dramatic velocity change (velocity trough and peak of the low velocity points in the dead zones) took place in even less than 0.5 second, indicating that within 10 seconds, sufficient flow motion periods were obtained. Therefore, the simulation results of the flow field in 2 to 10 seconds revealed the general agitation performance in different conditions. Because of the rotation of the bubble plumes, the whole velocity field varies at each time second and distributed asymmetrically. To avoid occasionality, the low velocity regions and dead zones which are of great focus in this work, are investigated and presented with time interval 0.25 second (e.g., Figure 6) or 0.5 second (e.g., Figure 7) during 2 to 10 seconds. More specifically, the absolute value of the matte velocity at the low velocity points and the dead zone volume fraction variation in the agitation zone were recorded, the results of which were used as bases for describing and evaluating the agitation behavior.

\section{Original tuyere diameter with correspondingly reduced gas injection speed}

The new tuyere arrangements were first tested with the original tuyere diameter and a gas injection speed of $23.67 \mathrm{~m} \mathrm{~s}^{-1}$. The test results of the velocity distribution in the tuyere sections, including Sections I and II, are shown in Figure 8. Generally, the regions shown in purple in Figure 8 beneath the bath level are the high velocity regions which overlap with the bubble plume, and the dark blue area represents the low velocity regions or dead zones. For the new tuyere arrangements with different angles from 14 to $18 \mathrm{deg}$, the single tuyere section (Section II) have bigger light blue areas, which means that a comparatively more uniform velocity distribution with almost no dead zone has been achieved. Moreover, the dark blue regions are small and randomly distributed, indicating that the dead zone does not exist for a long time. The agitation performance in the double tuyere sections (Section I) is not as 

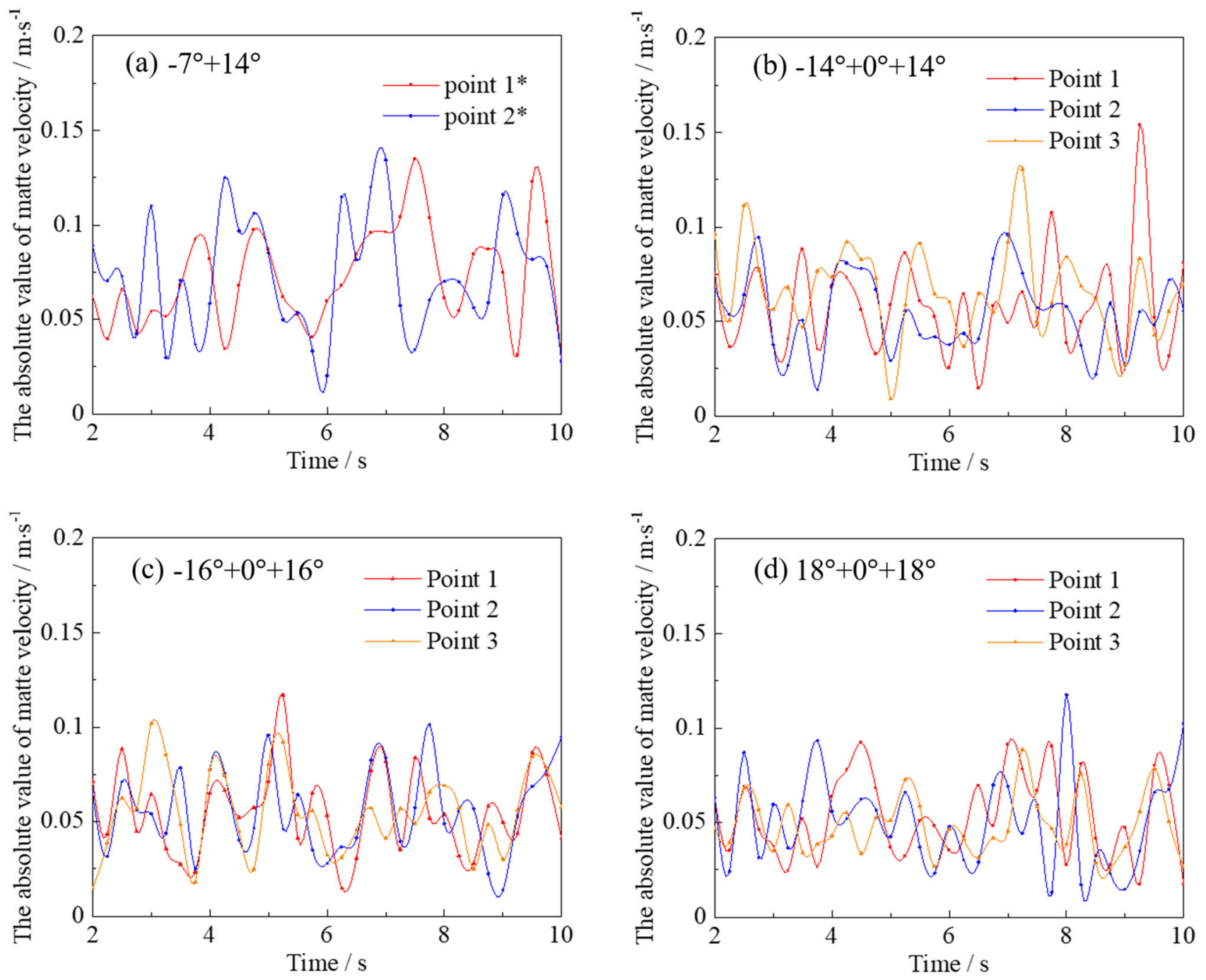

Fig. 6-Variation in the absolute value of the matte velocity at Points $1^{*}, 2^{*}$, and 1 to 3 from 2 to $10 \mathrm{~s}$. Gas injection speed $=23.67 \mathrm{~m} \mathrm{~s}{ }^{-1}$, tuyere diameter $=5 \mathrm{~mm}$, pool depth $=120 \mathrm{~mm}$. Chart $(a)$ : tuyere angle: $-7+14 \mathrm{deg}$. Chart $(b)$ : tuyere angle: $-14+0+14 \mathrm{deg}$. Chart $(c)$ : tuyere angle: $-16+0+16 \mathrm{deg}$. Chart $(d)$ : tuyere angle: $-18+0+18 \mathrm{deg}$. The image of tuyere angle: $-7+14$ deg is reprinted from our previous study ${ }^{[17]}$

good as in the single tuyere sections. It may be that large low velocity regions always exist, regardless of the tuyere angles, and may even cover a slightly larger area than those in the previously optimized case. This suggests that the new tuyere arrangements in the current conditions cannot provide stronger agitation near the double tuyere sections. The low velocity regions in Section I are mainly located at the furnace bottom between the two bubble plumes and the near side wall region on each side of the furnace.

To monitor the velocity variation in these low velocity regions, Points 1 to 3 in Figure 5 were chosen; this is shown in Figures 6(a) through (d). In comparison with the velocity variation for the $-7+14$ deg arrangement, at 2 to 10 seconds the $-x+0+x$ deg arrangements did not effectively improve the behavior at the low velocity points, but kept them quiet at below $0.15 \mathrm{~m} \mathrm{~s}^{-1}$ most of the time. When the tuyere angle was over $14 \mathrm{deg}$, the velocity performance was even worse, and mostly below $0.1 \mathrm{~m} \mathrm{~s}^{-1}$. This suggests that the original tuyere diameter with a correspondingly low initial injection speed was unable to provide stronger agitation in low velocity regions in the double tuyere sections, even though the number of tuyeres had been increased.

In comparison with the previously optimized two-line tuyere arrangement, better agitation performance in the middle area between the tuyeres is to be expected when adopting the new tuyere arrangements, as more tuyeres have been added and distributed in three lines. The velocity distribution in the middle sections during interactions between adjacent bubble plumes is shown in Figure 9. However, compared to the large low velocity regions that appear in Sections IV and V of the previous arrangement $(-7+14 \mathrm{deg})$, the low velocity regions under the new tuyere arrangements have shrunk considerably. Moreover, the agitation in the central area, which would be near the matte surface, is also strengthened. This could be attributed to the impact overlapping caused by the closest three tuyeres, rather than by the two tuyeres as before. Since both the 


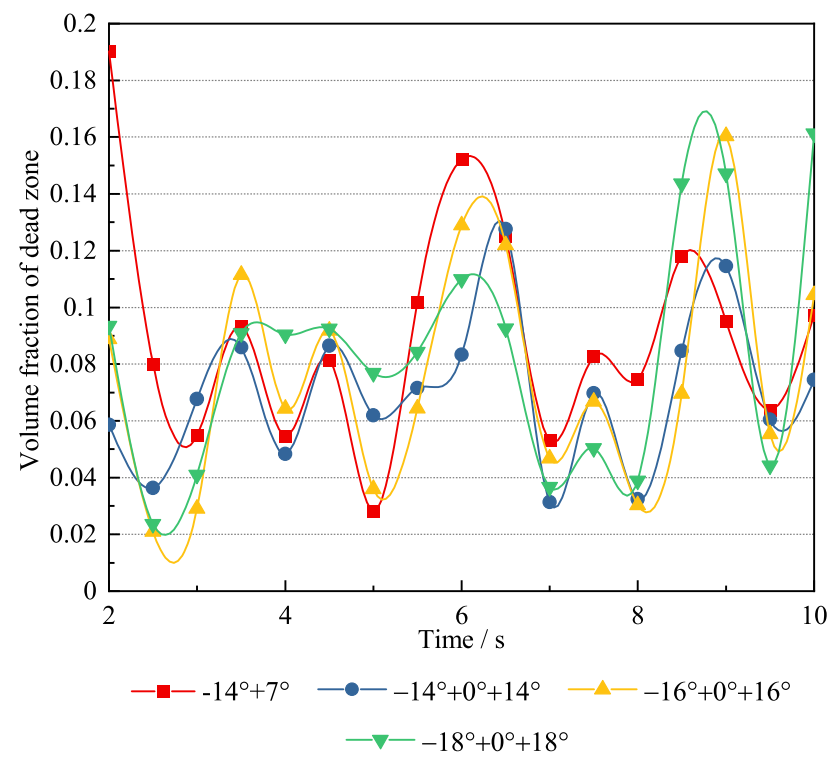

Fig. 7-Variation in dead zone volume fraction in the agitation zone with different tuyere angles from 2 to $10 \mathrm{~s}$. Gas injection speed = $23.67 \mathrm{~m} \mathrm{~s}^{-1}$, tuyere diameter $=5 \mathrm{~mm}$, pool depth $=120 \mathrm{~mm}$.

comparatively high and low velocity regions show good performance as expected, it can be concluded that the new $-x+0+x$ deg tuyere arrangements are able to supply a more evenly distributed agitation in the middle sections. However, such an enhancement does not seem to be strongly associated with small changes in the tuyere angles, as no obvious differences could be found in the tested tuyere angle range of 14 to $18 \mathrm{deg}$.

The variation in the dead zone volume fraction in the agitation zone, shown in Figure 7, is comprehensive proof of agitation performance. According to Figure 7, the dead zone volume of the $-x+0+x$ deg cases does not shrink; it even shows an increasing trend with more dramatic fluctuation than when the tuyere angle was 16 and $18 \mathrm{deg}$. Therefore, the $-x+0+x$ deg arrangements with the original tuyere diameter at a comparatively lower gas injection speed are not able to effectively reduce the dead zone volume. It was also found that the almost unchanged dead zone volume strongly agreed with the velocity variation behavior of low velocity points, as presented in Figure 6. This indicates that, in current conditions, the dead zones are mainly located in the regions between bubble plumes and the side walls, but not in the middle areas such as the investigated Sections III-V.

The bottom wall shear stress is a key point that affects the lining refractory lifespan and is simultaneously reflected in the interactions between the matte phase and the wall. The wall shear stress under both the previously optimized and the new tuyere arrangements is depicted in Figure 10. According to our previous study, the impact on the bottom and side wall would be strengthened when the two lines of tuyeres become closer, which could be attributed to the overlapping of the wall shear stress. Similarly, this phenomenon can also be found in the $-x+0+x$ deg tuyere arrangements. With the increase in tuyere angle from 14 to
$18 \mathrm{deg}$, the wall shear stress slightly decreases in the areas surrounding the tuyeres. Such a decrease may also be supported by the agitation behavior shown in Figure 6, as the low velocity regions for tuyere angle $x$ $=14 \mathrm{deg}$ seem slightly more active than with tuyere angle $x=16$ or $18 \mathrm{deg}$. Combined with the performance of the low velocity regions, the slight change in wall shear stress at different tuyere angles was well explained. Variation in wall shear stress was noticed with changes in tuyere angle, but generally the wall shear stresses shown in Figure 6 are at the same level, which suggests that the impact on the wall is acceptable under the current simulation conditions.

Based on the results discussed in this chapter, the $-x+0+x$ deg tuyere arrangements with the original tuyere diameter and a relatively lower gas injection speed deliver better agitation behavior in the single tuyere sections (Section II) and middle sections (Sections III-V), but for the double tuyere sections (Section I), large regions of low velocity remained. In general, the velocity field was not significantly intensified, nor were the interactions between the matte phase and furnace wall; hence the wall shear stress was maintained within a good range.

2. Original tuyere diameter with correspondingly reduced gas injection speed in an elliptical furnace

The agitation performance was not significantly improved by the new tuyere arrangements with the original tuyere diameter. To further enhance the agitation, the elliptical furnace body was tested with the same fixed tuyere diameter and injection speed as those given in subchapter $\mathrm{IV}-\mathrm{A}-\mathrm{i}$.

A comparison of the velocity distribution between the elliptical furnace and the previous cases is shown in Figure 11. As expected, the agitation has been enhanced by the higher aspect ratio in the elliptical furnace models. In Section I, there are no areas at all in dark blue in the case of aspect ratios 1.1:1 and 1.2:1, showing a well distributed velocity field in the bath; in Section II, more light blue areas appear, suggesting further enhanced agitation performance. For the elliptical furnace, the distance between bubble plumes and side wall has been reduced by the increased aspect ratio and, therefore, the interactions are enhanced, causing a more active velocity distribution. Under the current conditions, the shape of the elliptical furnace has a positive effect on its internal flow field, i.e., stronger agitation and an almost eliminated dead zone in both the single and double tuyere sections.

To verify the performance in the double tuyere sections, long-term velocity variation curves in the range of 2 to 10 seconds for the low velocity points in Figure 11 are shown in Figure 12. When the aspect ratio was adjusted from 1:1 (round) to $1.1: 1$, the velocity values of Points 1-3 remained in a low range below 0.15 $\mathrm{m} \mathrm{s}^{-1}$, with only a surge at $10 \mathrm{~s}$. This means the agitation in the low velocity region of the aspect ratio 1.1:1 furnace model might not be as strong as that shown in Figure 11. However, when the aspect ratio was further increased to 1.2:1, the velocity regions became much more active, indicating that stronger agitation in 


\section{Matte velocity distribution in the range of $0-1 \mathrm{~m} \cdot \mathrm{s}^{-1}$}

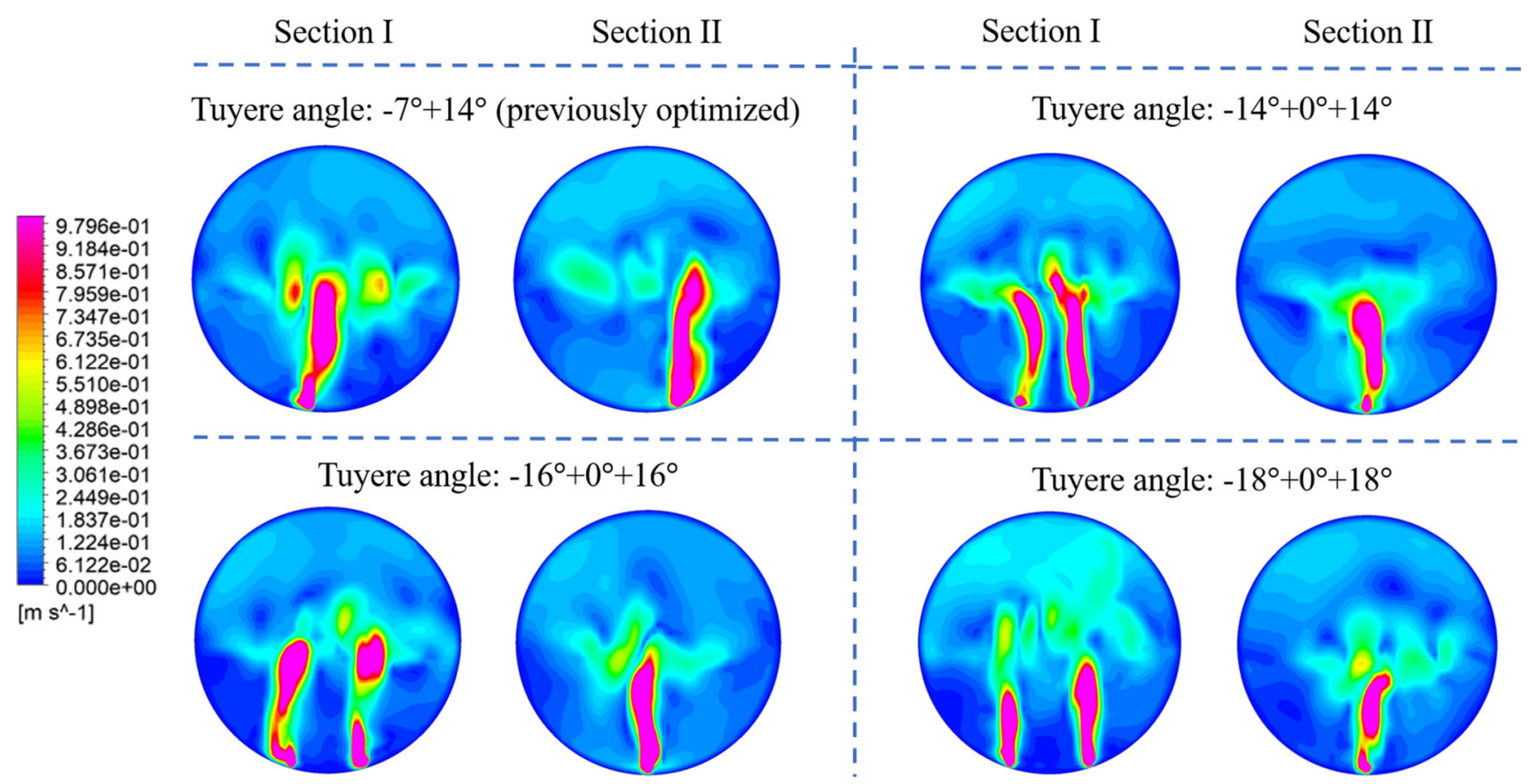

Fig. 8-Matte velocity distribution in Sections I and II of the simulated scaled-down SKS furnace at $10 \mathrm{~s}$. Gas injection speed $=23.67 \mathrm{~m} \mathrm{~s}{ }^{-1}$, tuyere diameter $=5 \mathrm{~mm}$, pool depth $=120 \mathrm{~mm}$. The images of tuyere angle: $-7+14 \mathrm{deg}$ are reprinted from our previous study ${ }^{[17]}$

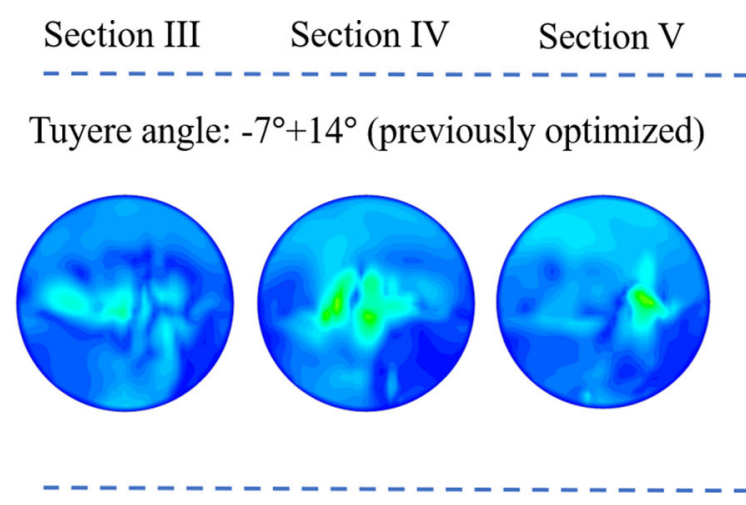

Tuyere angle: $-16^{\circ}+0^{\circ}+16^{\circ}$

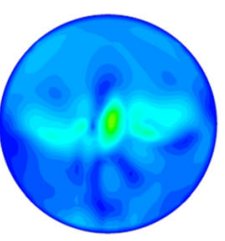

Section III Section IV Section V

Tuyere angle: $-14^{\circ}+0^{\circ}+14^{\circ}$
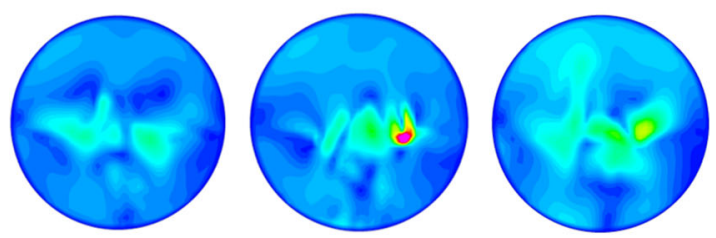

Tuyere angle: $-18^{\circ}+0^{\circ}+18^{\circ}$
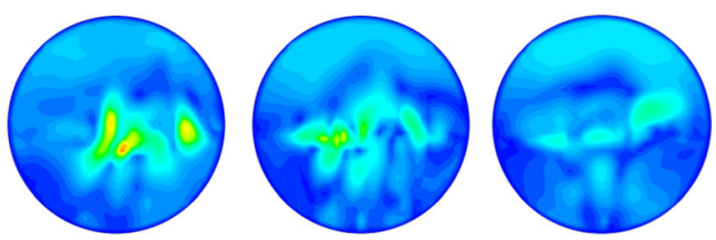

Fig. 9-Matte velocity distribution in Sections III-V of the simulated scaled-down SKS furnace at $10 \mathrm{~s}$. Gas injection speed $=23.67 \mathrm{~m} \mathrm{~s}^{-1}$, tuyere diameter $=5 \mathrm{~mm}$, pool depth $=120 \mathrm{~mm}$. The images of tuyere angle: $-7+14$ deg are reprinted from our previous study ${ }^{[17]}$

the low velocity regions had been achieved. This further proves that the elliptical furnace contributes to promoting the agitation behavior significantly in the low velocity regions in the tuyere sections. The velocity distribution between the tuyere sections or bubble plumes is shown in Figure 13, where a similar regular pattern can be found. The cases of aspect ratios 1:1 and 1.1:1 both have more uniformed velocity distribution 


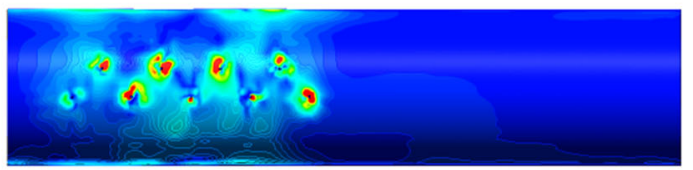

Tuyere angle: $-16^{\circ}+0^{\circ}+16^{\circ}$

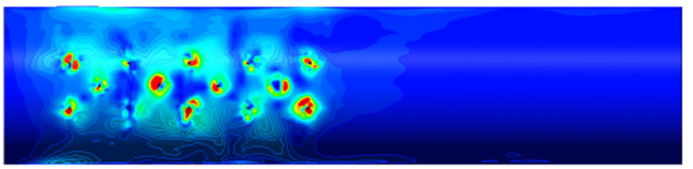

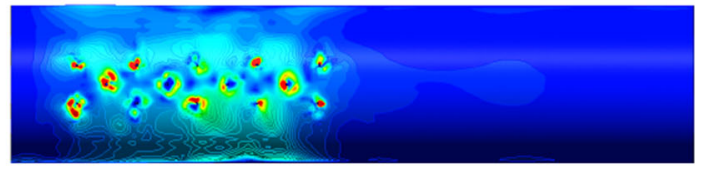

Tuyere angle: $-18^{\circ}+0^{\circ}+18^{\circ}$

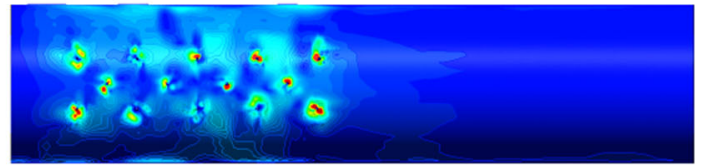

Fig. 10-Bottom view of the matte wall shear stress of the simulated scaled-down SKS furnace at $10 \mathrm{~s}$. Gas injection speed $=23.67 \mathrm{~m} \mathrm{~s}^{-1}$, tuyere diameter $=5 \mathrm{~mm}$, pool depth $=120 \mathrm{~mm}$. The image of tuyere angle: $-7+14 \mathrm{deg}$ is reprinted from our previous study ${ }^{[17]}$

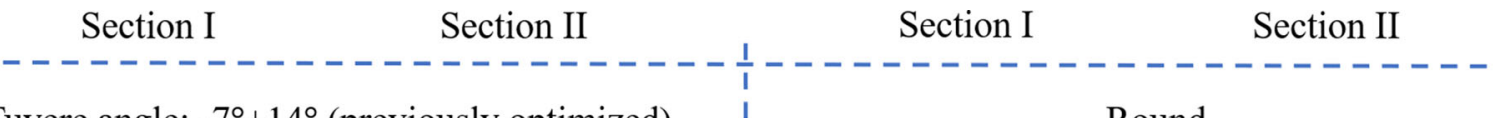

Tuyere angle: $-7^{\circ}+14^{\circ}$ (previously optimized)
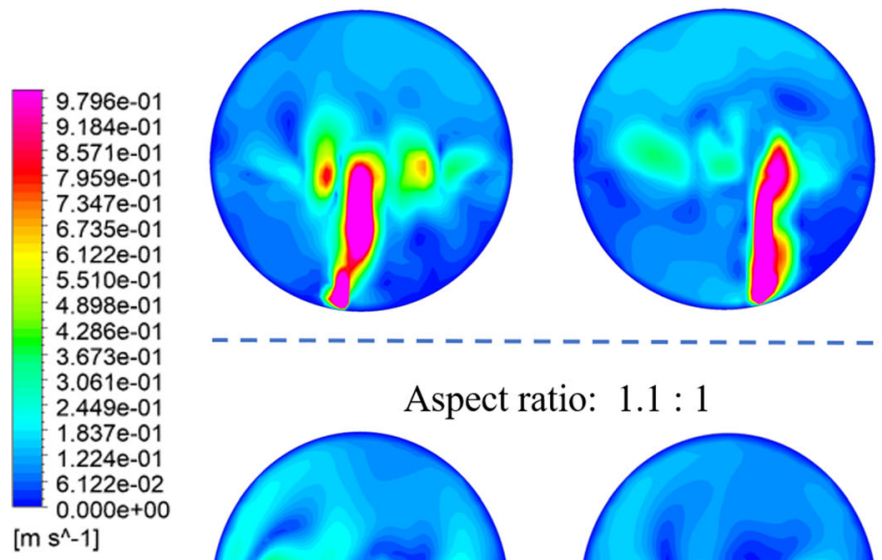

Aspect ratio: $1.1: 1$
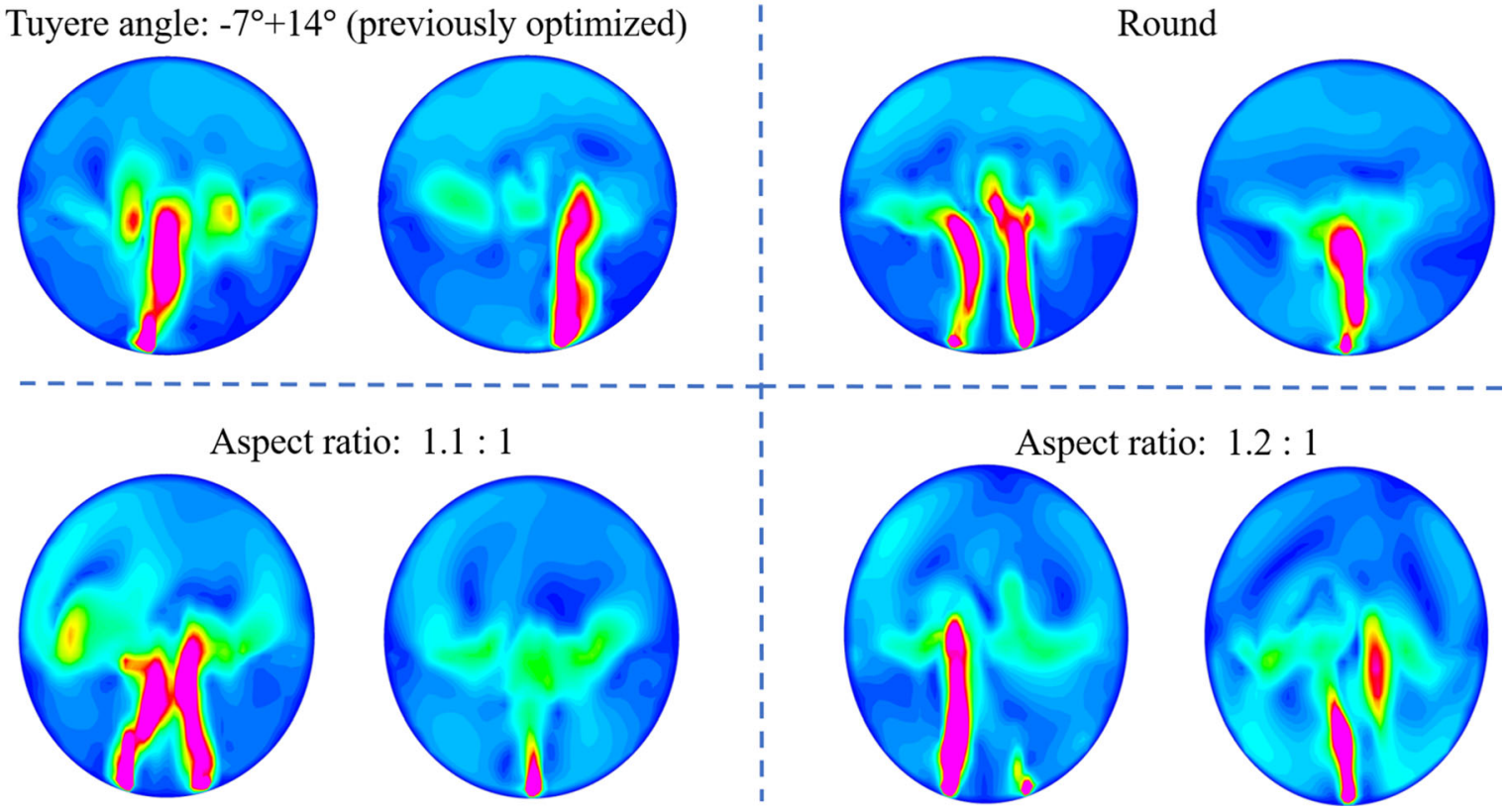

Fig. 11-Matte velocity distribution in Sections I and II of the simulated round and elliptical scaled- down SKS furnaces at $10 \mathrm{~s}$. Tuyere angle for new arrangements: $-14+0+14 \mathrm{deg}$, Gas injection speed $=23.67 \mathrm{~m} \mathrm{~s}^{-1}$, Tuyere diameter $=5 \mathrm{~mm}$, pool depth $(\mathrm{mm}) /$ furnace height $(\mathrm{mm})$ $=120: 145$. The pool depth in the elliptical furnace was adjusted according to the aspect ratio to make the bath level height a certain proportion of the total furnace height, which is the same as that in the round furnace case. The images of tuyere angle: $-7+14$ deg are reprinted from our previous study ${ }^{[17]}$

than that in the previous optimized model. Stronger agitation could be noticed in the case of an aspect ratio of $1.2: 1$, with not only an almost eliminated dead zone but also expanded green and red areas, which means a further enhanced high velocity region. Therefore, according to the above investigation of Sections I-V, good agitation performance has been implemented by the change in the furnace body structure, from round to elliptical geometry.

The dead zone volume fraction in the agitation zone is shown in Figure 14, representing the general agitation performance in the elliptical furnace models. Dead zone volumes have been greatly reduced in the elliptical furnace models in comparison with the round furnace models. Combined with the velocity distribution discussed in Figure 11, it is reasonable to deduce that the dead zone has been suppressed by the stronger interactions caused by the narrowed furnace body.

The purpose of the change in furnace structure from round to elliptical is precisely to enhance the interactions between the bubble plumes and the furnace side wall. However, this enhancement should be limited to avoid unacceptable impairment of the wall lining refractory because, once the agitation is intensified, the wall shear stress will be increased. The bottom view of the matte wall stress for the elliptical furnace model at different aspect ratios is shown in Figure 15. Compared to the situation in the previous optimized case and the 


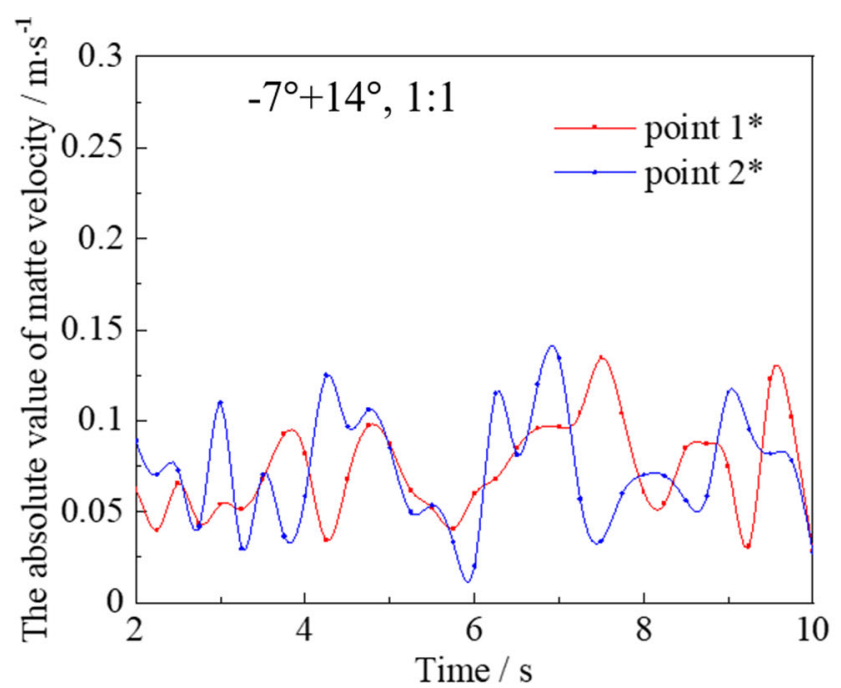

(a)

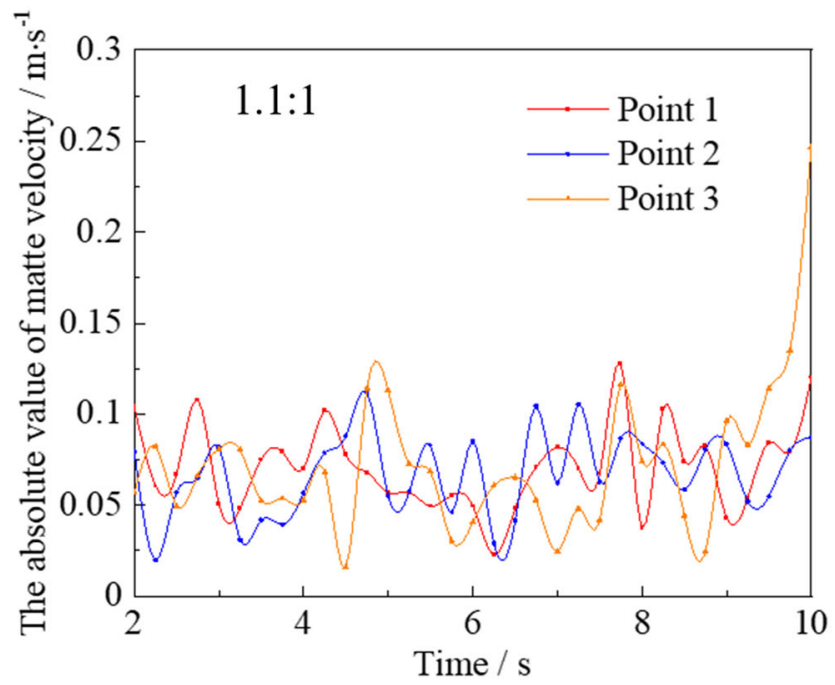

(c)

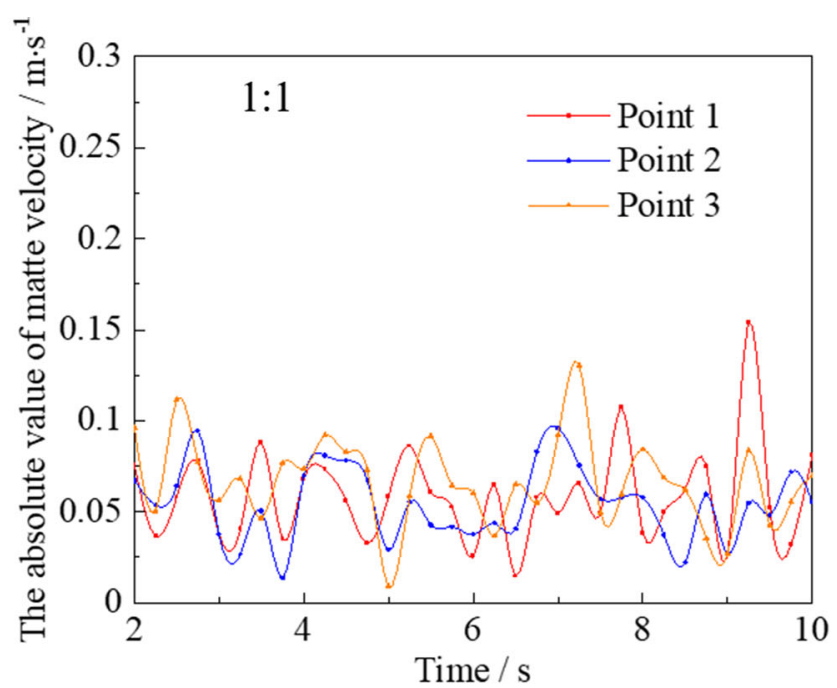

(b)

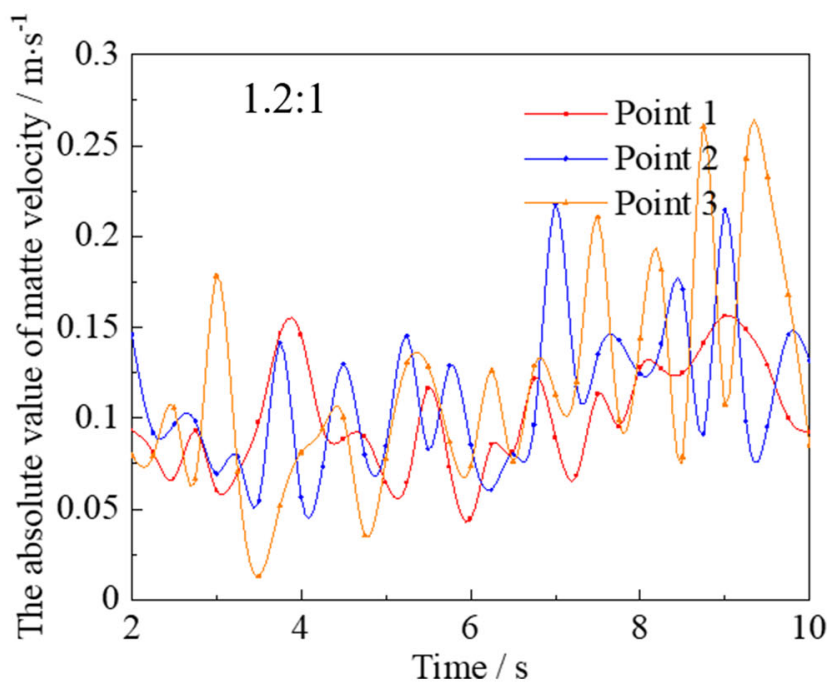

(d)

Fig. 12-Variation in the absolute value of the matte velocity (in Figure 10) at Points $1^{*}, 2^{*}$, and 1 to 3 from 2 to $10 \mathrm{~s}$. Gas injection speed = $23.67 \mathrm{~m} \mathrm{~s}^{-11}$, tuyere diameter $=5 \mathrm{~mm}$. Pool depth $(\mathrm{mm}) /$ furnace height $(\mathrm{mm})=120: 145$. Chart $($ a $)$ : tuyere angle: $-7+14$ deg, aspect ratio: 1:1. Chart $(b)$ to $(d)$ : tuyere angle: $-14+0+14 \mathrm{deg}$, aspect ratio: from $1: 1$ to $1.2: 1$, respectively. The image of tuyere angle: $-7+14$ deg is reprinted from our previous study. ${ }^{[17]}$

round furnace case, the light blue areas start to be larger in the elliptical furnace with an aspect ratio of 1.1:1, which suggests a stronger impact on the side wall. This growing impact becomes more noticeable when the aspect ratio is further increased to 1.2:1, in which the wall shear stress on the side wall is as large as the stress near the tuyere region. Such a strong impact might not be acceptable because it has been reported that the furnace refractory life span depends largely on the wall shear stress in the regions surrounding tuyeres. ${ }^{[9]}$ Therefore, once the side wall is subjected to an impact at the same level as the tuyere region, the lining refractory will also be put at risk.

In general, using the $-x+0+x$ deg tuyere arrangements, the elliptical furnace model has proved to be able to provide stronger agitation compared with the round furnace case. However, it should be noted that, with the promotion of agitation behavior, the impact on the side wall will also become more severe. Although a more balanced condition may possibly be found between the aspect ratios of 1.1:1 and 1.2:1, other challenges may be encountered with regard to the elliptical furnace structure. The elliptical furnace has been tested on Maerz technology ${ }^{[23]}$; unfortunately, the furnace body presents a challenge regarding mechanical strength. Despite the potential risks, the elliptical furnace also has its own potential advantages, including a longer floating gas trajectory and less slag-matte contact, which would help to increase the gas uphold and decrease the copper loss in the slag phase. In this work, the CFD test results suggest agitation enhancement in elliptical furnaces. A more detailed investigation is recommended when more advanced refractories and supporting technologies have been achieved. 
Tuyere angle: $-7^{\circ}+14^{\circ}$ (previously optimized)
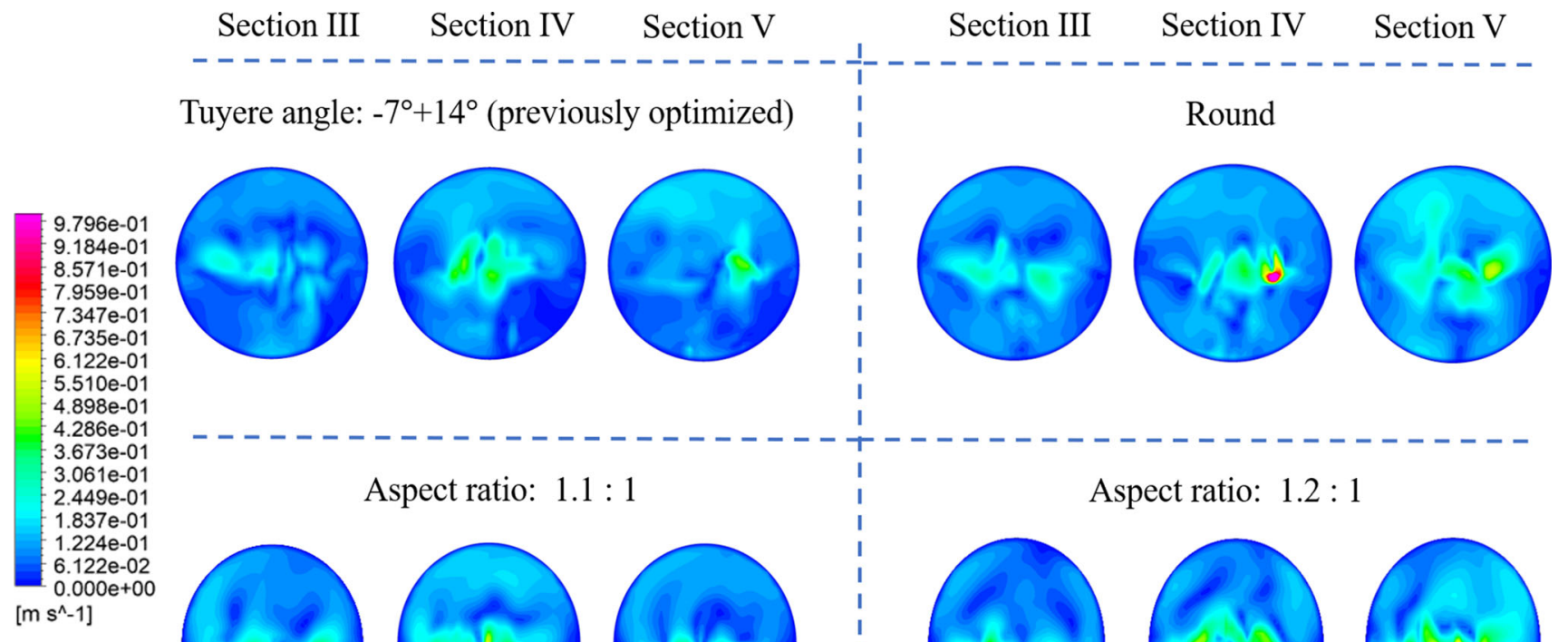

Aspect ratio: $1.1: 1$
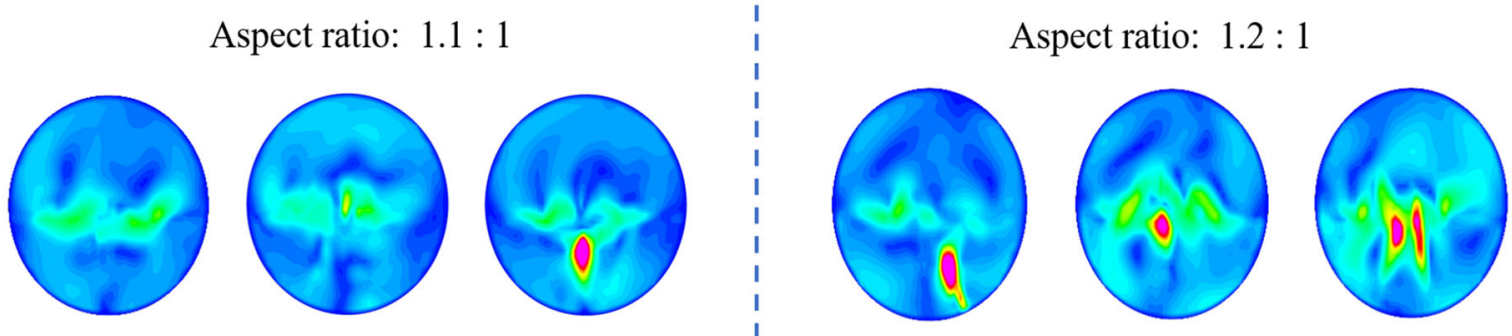

Fig. 13-Matte velocity distribution in Sections III-V of the simulated round and elliptical scaled-down SKS furnace at $10 \mathrm{~s}$. Tuyere angle for the new arrangements: $14+0+14 \mathrm{deg}$, gas injection speed $=23.67 \mathrm{~m} \mathrm{~s}^{-1}$, tuyere diameter $=5 \mathrm{~mm}$, POOL depth $(\mathrm{mm}) /$ furnace height $(\mathrm{mm})$ $=120: 145$. The pool depth in the elliptical furnace is adjusted according to the aspect ratio to make the bath level height a certain proportion of the total furnace height, which is the same as that in the round furnace case. The images of tuyere angle: $-7+14$ deg are reprinted from our previous study ${ }^{[17]}$

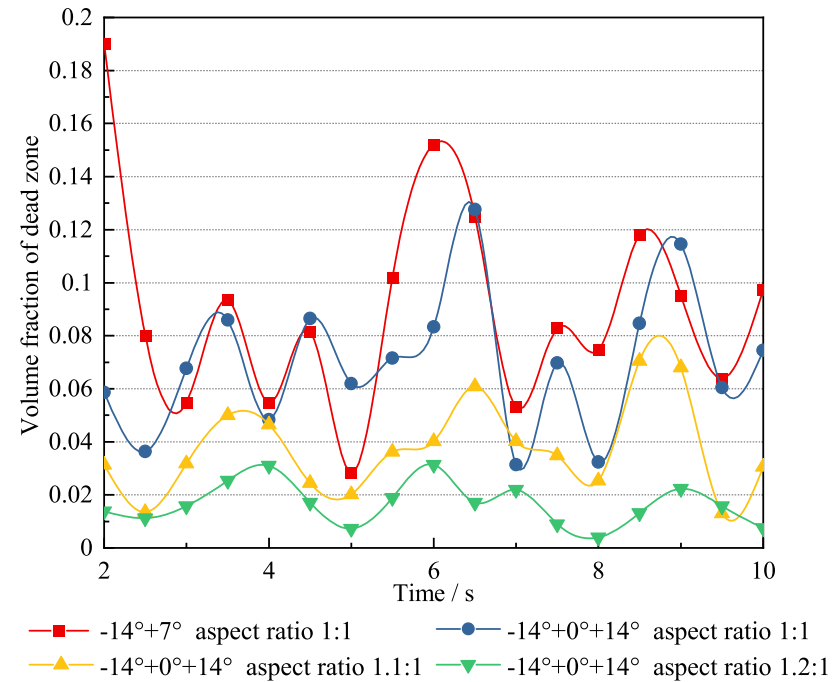

Figure 14-Variation in the dead zone volume fraction in the agitation zone with different aspect ratios from 2 to $10 \mathrm{~s}$ in elliptical models. Gas injection speed $=23.67 \mathrm{~m} \mathrm{~s}^{-1}$, Tuyere diameter $=5$ $\mathrm{mm}$, Pool depth $(\mathrm{mm}) /$ furnace height $(\mathrm{mm})=120: 145$.

3. Original gas injection speed with correspondingly smaller tuyere diameter

Apart from the change in furnace structure, another approach for improving agitation performance is to increase the gas injection speed. The testing of the same original gas injection speed of $36.80 \mathrm{~m} \mathrm{~s}^{-1}$ as the previously optimized $-7+14 \mathrm{deg}$ case is described in this subchapter. To enable comparison with the previously discussed cases in subchapters 4.1.1 and 4.1.2, the total volumetric gas flow rate was unchanged and, therefore the tuyere diameter was accordingly decreased from the original $5 \mathrm{~mm}$ to $4 \mathrm{~mm}$.

The velocity distribution for the $-x+0+x$ deg tuyere arrangements, at the original gas injection speed of $36.80 \mathrm{~m} \mathrm{~s}^{-1}$ and the smaller tuyere diameter of $4 \mathrm{~mm}$, is shown in Figure 16. In general, stronger agitation has been achieved compared to the previously optimized case. As the gas injection speeds for the $-x+0+x$ deg tuyere arrangements were not further increased, the enhanced velocity field can be attributed to the additional tuyere that was added in the new tuyere arrangements. An unexpected velocity distribution can be seen in Section III. When the tuyere angle is arranged at $x=14 \mathrm{deg}$, with the exception of the plume regions, almost all the area below the bath level is in dark blue, which means a very quiet situation. Therefore, even if the original $36.80 \mathrm{~m} \mathrm{~s}^{-1}$ injection speed is adopted rather than the reduced $23.67 \mathrm{~m} \mathrm{~s}^{-1}$ discussed in previous chapters, enhanced agitation cannot always be assured. In both Sections III and IV, the light blue and green areas tend to expand with an increase in tuyere angle. This suggests that the agitation performance is in some way strongly associated with the tuyere angle setup and, obviously, a larger tuyere angle contributes to promoting agitation.

The observations from 2 to 10 seconds of the low velocity points in Figure 16 are shown in Figure 17. As can be seen, compared to the original optimized case with tuyere angles at $-7+14 \mathrm{deg}$, for the $-x+0+$ $x$ deg tuyere arrangements the velocity value for $x=16$ and $18 \mathrm{deg}$ is significantly increased, whereas the value 


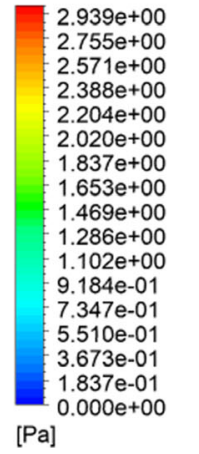

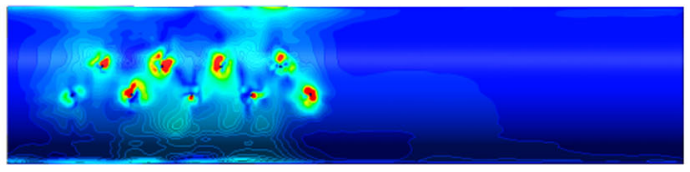

Aspect ratio: $1.1: 1$

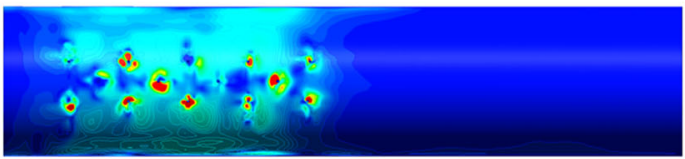

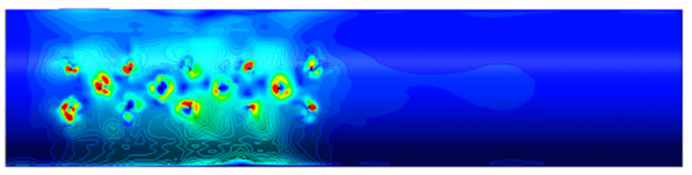

Aspect ratio: $1.2: 1$

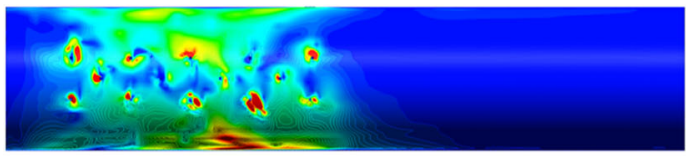

Fig. 15-Bottom view of the matte wall shear stress of the simulated scaled-down SKS furnace at 10 s. Tuyere angle for the new arrangements: $14+0+14 \mathrm{deg}$, Gas injection speed $=23.67 \mathrm{~m} \mathrm{~s}^{-1}$, Tuyere diameter $=5 \mathrm{~mm}$, Pool depth $(\mathrm{mm}) /$ furnace height $(\mathrm{mm})=120: 145$. The pool depth in the elliptical furnace is adjusted according to the aspect ratio to make the bath level height a certain proportion of the total furnace height, which is the same as that in the round furnace case. The image of tuyere angle: $-7+14$ deg is reprinted from our previous study. ${ }^{[1]}$

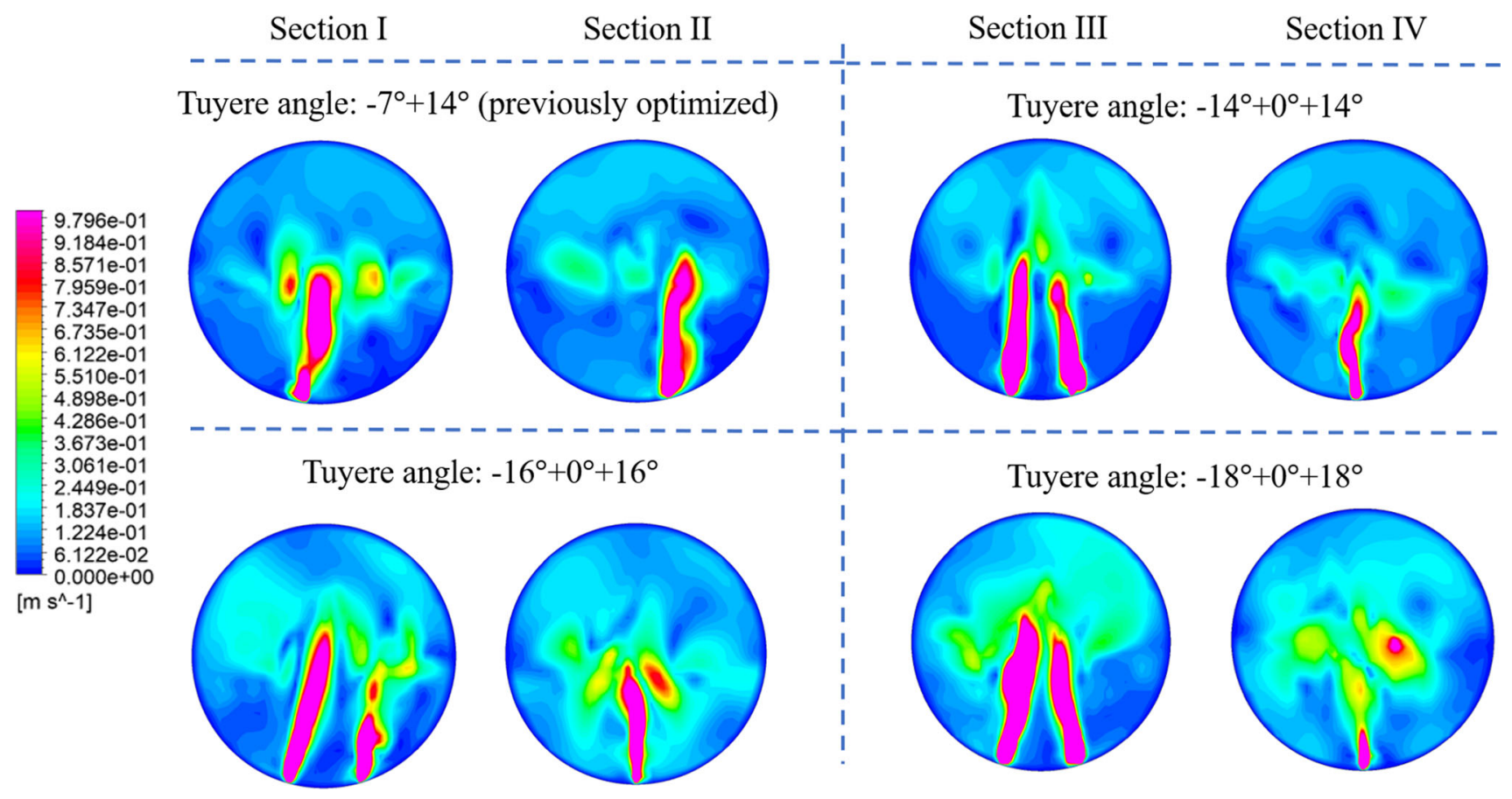

Fig. 16-Matte velocity distribution in Section I and Section II of the simulated scaled-down SKS furnace at $10 \mathrm{~s}$. Gas injection speed $=36.80$ $\mathrm{m} \mathrm{s}^{-1}$, Tuyere diameter $=4 \mathrm{~mm}$, Pool depth $=120 \mathrm{~mm}$. The image of tuyere angle: $-7+14$ deg is reprinted from our previous study. ${ }^{[17]}$

for $x=14 \mathrm{deg}$ is still at the original level. The long-term observation shows a similar regular pattern as that depicted in Figure 16. In addition, interestingly, the velocity at Point 2 , which is located between the two bubble plumes, is also improved by larger tuyere angles. Based on experience from previous studies, ${ }^{[17]}$ a larger difference in tuyere angles might weaken the interactions between adjacent bubble plumes and hence lead to a quieter velocity field, especially in the area between two lines of tuyeres. In contrast, the agitation in the center area between two bubble plumes is strengthened in these conditions. The reason might be the influence of the tuyeres on the center line at the furnace bottom. Also, the fully enhanced agitation at $x=16$ and 18 deg may further reduce the low velocity regions.

In the middle sections (Sections III-V) shown in Figure 18, the agitation promoted by increasing the tuyere angles becomes more obvious. Large green and light blue areas can be seen when the tuyere angle was increased to 16 and $18 \mathrm{deg}$, and there was almost no dead zone in the same position, which can be regarded as a well distributed velocity field. In these sections, even the velocity distribution at tuyere angle $x=14 \mathrm{deg}$ shows better agitation performance than those in the 


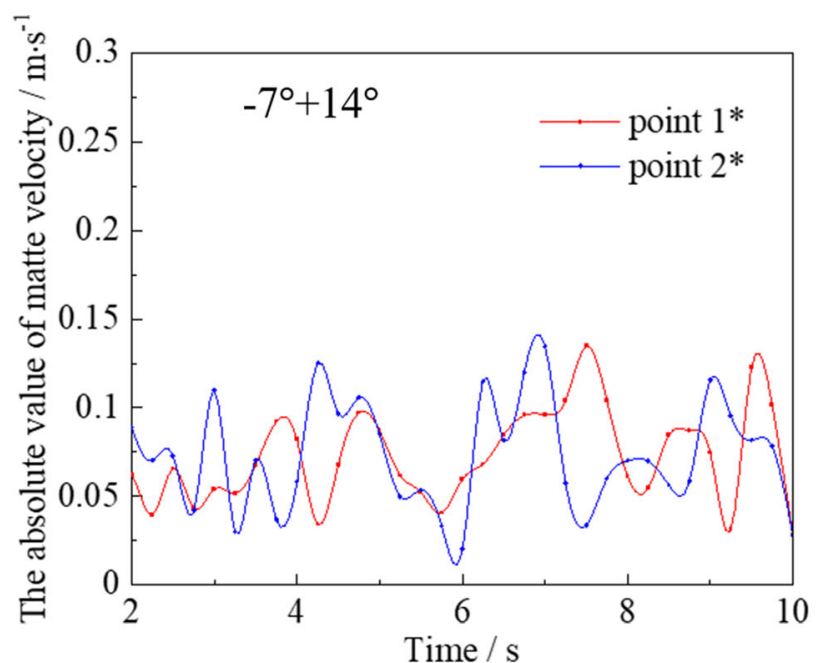

(a)

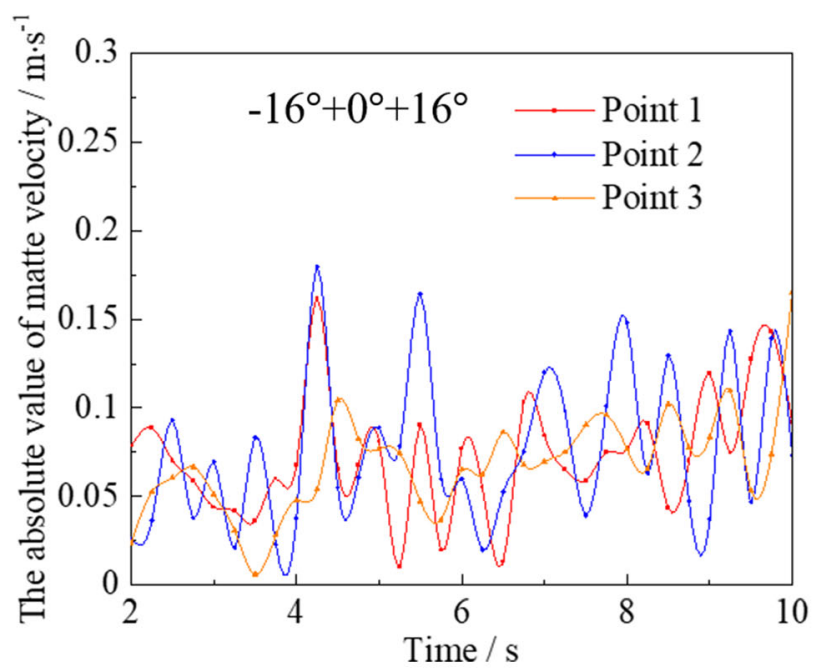

(c)

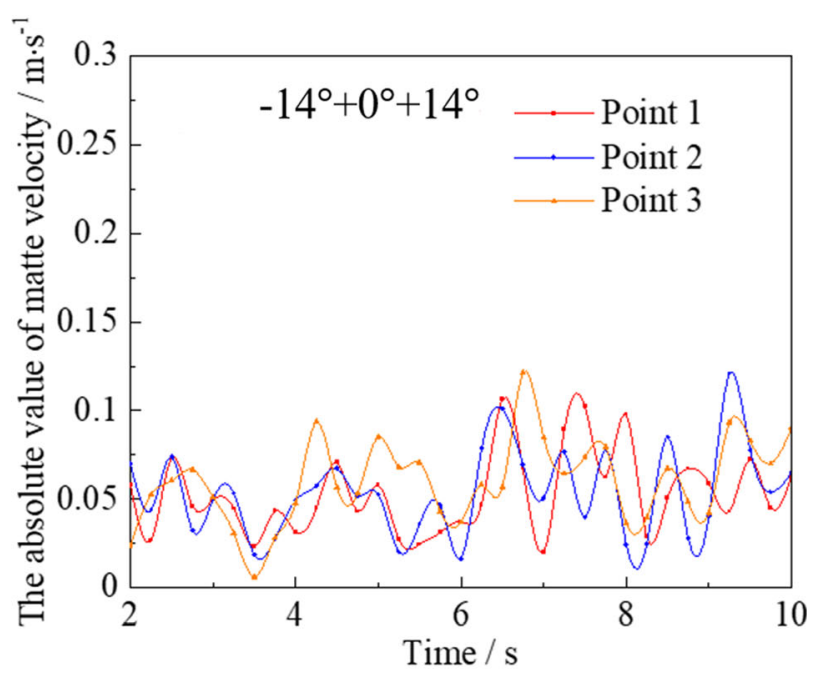

(b)

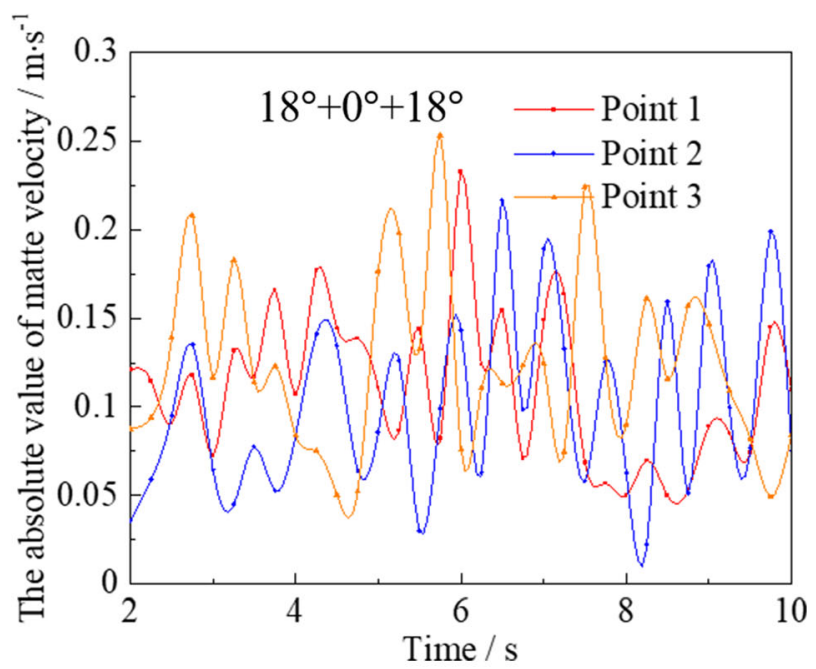

(d)

Fig. 17-Variation in the absolute value of the matte velocity at Points $1^{*}, 2^{*}$, and 1-3 (marked in Figure 5) in Figure 14 from 2 to 10 s. Gas injection speed $=36.80 \mathrm{~m} \mathrm{~s}^{-1}$, Tuyere diameter $=4 \mathrm{~mm}$, pool depth $=120 \mathrm{~mm}$. Chart $(a)$ : tuyere angle: $-7+14 \mathrm{deg}$. Chart $(b)$ : tuyere angle: $-14+0+14 \mathrm{deg}$. Chart $(c)$ : tuyere angle: $-16+0+16 \mathrm{deg}$. Chart $(d)$ : tuyere angle: $-18+0+18$ deg. The image of tuyere angle: $-7+14$ deg is reprinted from our previous study. ${ }^{[17]}$

previously optimized case. Combined with the situation described in subchapters 4.1.1 and 4.1.2, this indicates that, for the $-x+0+x$ deg tuyere arrangements, the agitation in regions between areas of double and single tuyeres tends to be more easily enhanced. In addition, in the relevant investigated sections including Sections III-V, all of the cases exhibit better performance than the optimized case in our previous study. ${ }^{[17]}$

The dead zone volume fraction variations of the cases in this chapter are shown in Figure 19. As can be seen, a smaller dead zone has been achieved with a higher tuyere angle. For cases with tuyere angles of 16 and $18 \mathrm{deg}$, the dead zone was significantly reduced, which is very consistent with the low velocity area exhibited in Figure 16. The investigated Sections $\mathrm{I}-\mathrm{V}$ and the variation in the dead zone volume fraction indicate that, in the current conditions, the tuyere arrangements of $-16+0+16 \mathrm{deg}$ and $-18+0+18 \mathrm{deg}$ are able to produce a comparatively wider agitation area, reducing the low velocity regions or dead zones to a low level in both the tuyere regions (near Sections I and II) and middle regions (near Sections III-V).

The wall shear stress for the tested cases described in this subchapter is shown in Figure 20, which could help to evaluate the impact on the wall refractory and simultaneously explain the relationship between agitation behaviors with different tuyere angles. According to Figure 20, the wall shear stress increases with increasing tuyere angles in proportion to the enhancement of agitation. Therefore, it can be deduced that the better agitation performance with larger tuyere angles can be attributed to stronger interactions between the bubble plumes and the side wall. From this point of view, with a comparatively higher gas injection speed, the increase in 


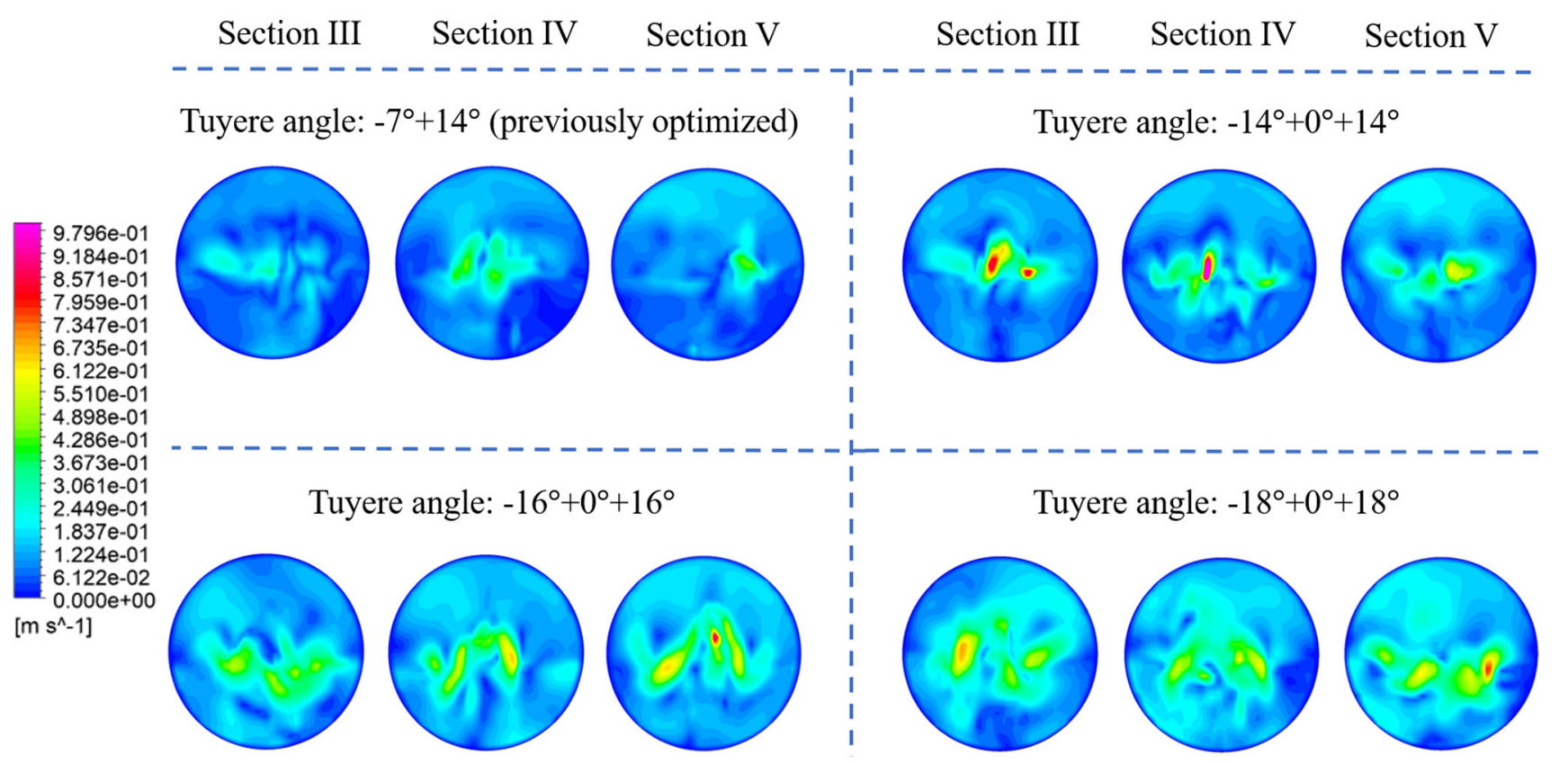

Fig. 18-Matte velocity distribution in Sections III-V of the simulated scaled-down SKS furnace at $10 \mathrm{~s}$. Gas injection speed $=36.80 \mathrm{~m} \mathrm{~s}{ }^{-1}$, tuyere diameter $=4 \mathrm{~mm}$, pool depth $=120 \mathrm{~mm}$. The image of tuyere angle: $-7+14 \mathrm{deg}$ is reprinted from our previous study. ${ }^{[17]}$

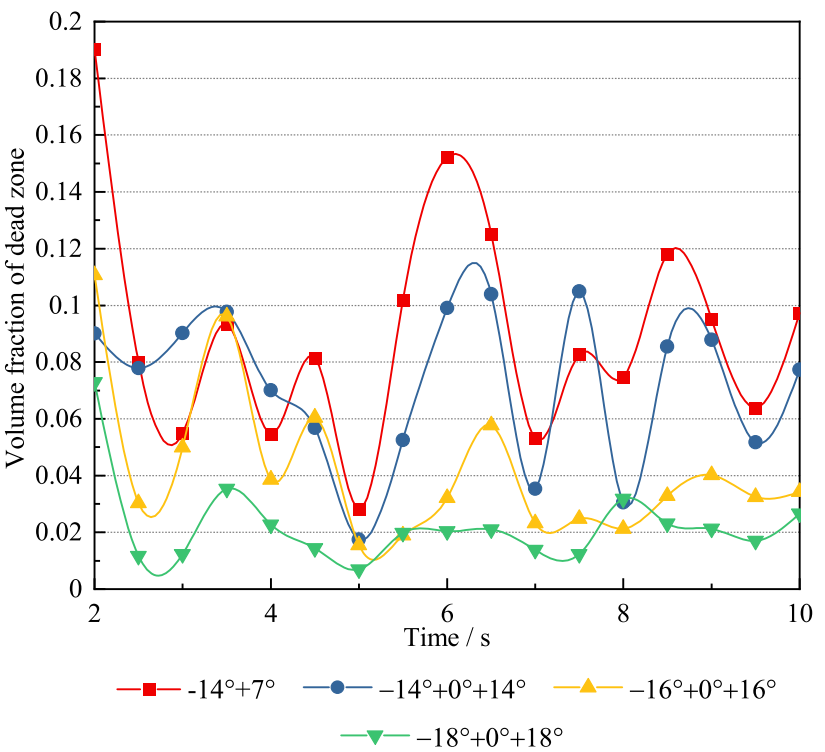

Fig. 19-Variation in the dead zone volume fraction in the agitation zone with different tuyere angles from 2 to $10 \mathrm{~s}$ in elliptical models. Gas injection speed $=36.80 \mathrm{~m} \mathrm{~s}^{-1}$, tuyere diameter $=4 \mathrm{~mm}$, Pool depth $=120 \mathrm{~mm}$.

tuyere angles and the usage of an elliptical furnace structure promote agitation in essentially the same way. The bubbles or the bubble-driven matte have a horizontal velocity component, and would come into contact with the walls, then be pushed back by the wall counterforce. In the case of a larger tuyere angle or an elliptical furnace, the distance between the plume and wall is shortened, hence the bubbles or matte are pushed back earlier, with less velocity loss. Therefore, the agitation in the low velocity area near the walls is enhanced, and the walls are subjected to greater impact. In both approaches, the core reason for an intensified velocity field is that the interactions between the gas plumes and side walls have been strengthened.

In general, when the original gas injection speed is adopted, an increase in the tuyere angle can efficiently eliminate the low velocity regions and significantly promote agitation. In comparison with the elliptical furnace, such a tuyere angle change would not challenge the mechanical strength of the furnace; in fact, the parameters used have already been proven in industry. According to the results described in this chapter, for the $-x+0+x$ deg tuyere arrangements both the velocity distribution and wall shear stress are in an acceptable range when $x=16 \mathrm{deg}$. As shown in Figures 16 through 19, the low velocity area or dead zone has been almost eliminated and stronger agitation formed. As shown in Figure 20, the wall shear stress in the side wall area increased a little, but was still at the same level as that near the tuyere area, which indicates that the furnace life span would not be significantly affected. Based on this, it was determined that the $-16+0+16$ deg arrangement deserved further study and an agitation test. In the next subchapter, a full-scale model is described regarding this tuyere arrangement.

\section{B. Simulated Full-Scale SKS Model with an Optimized $-x+0+x$ Deg Tuyere Arrangement}

A full-scale furnace model was constructed to test the performance of the optimized $-x+0+x$ deg tuyere arrangement with practical design parameters, referring to the Fangyuan furnace. ${ }^{[25]}$ The general gas injection 


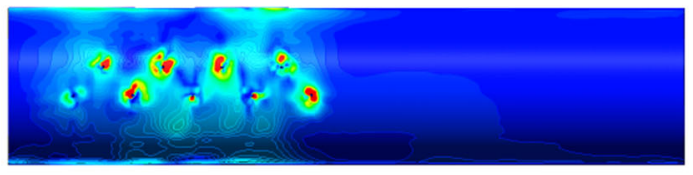

Tuyere angle: $-16^{\circ}+0^{\circ}+16^{\circ}$

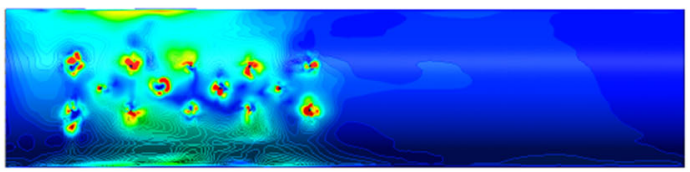

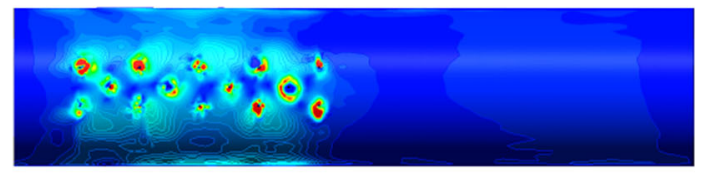

Tuyere angle: $-18^{\circ}+0^{\circ}+18^{\circ}$

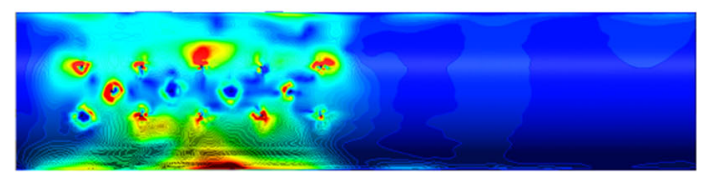

Fig. 20-Bottom view of the matte wall shear stress of the simulated scaled-down SKS furnace at $10 \mathrm{~s}$. Gas injection speed $=36.80 \mathrm{~m} \mathrm{~s}^{-1}$, tuyere diameter $=4 \mathrm{~mm}$, pool depth $=120 \mathrm{~mm}$. The image of tuyere angle: $-7+14$ deg is reprinted from our previous study. ${ }^{[17]}$

Scaled-down furnace model
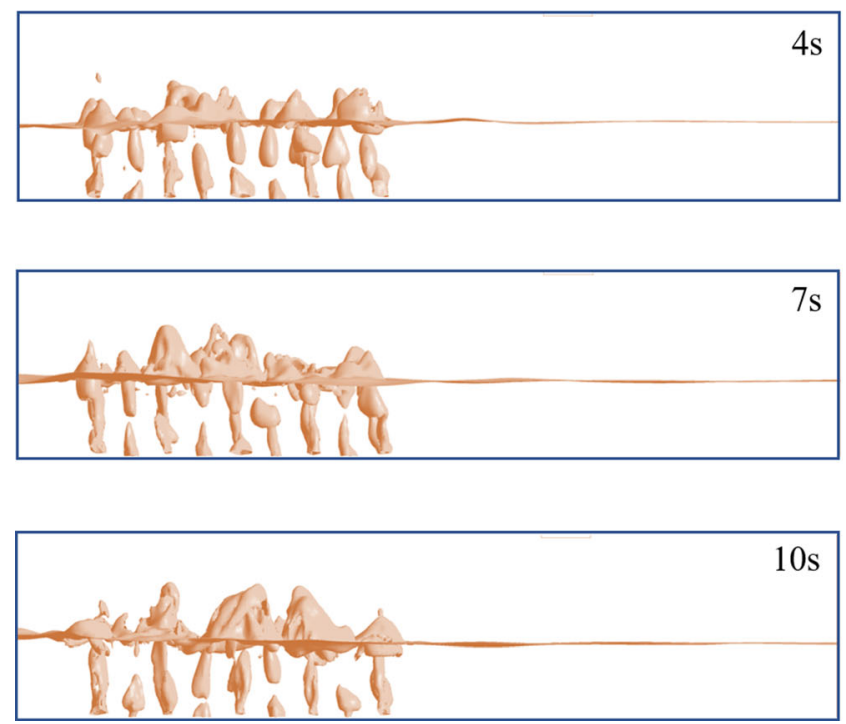

Full-scale furnace model
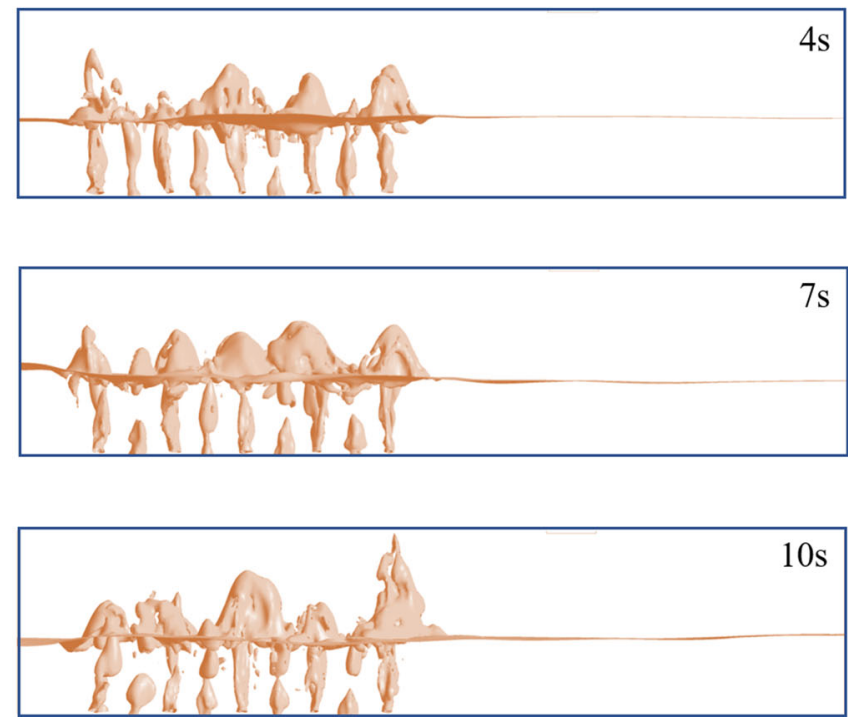

Fig. 21 - Side view of the simulated scaled-down and full-scale SKS furnaces at 4, 7, and $10 \mathrm{~s}$. The iso-surface, shown in orange, is the air-matte interface with an air volume fraction of 0.5 (Color figure online).

behavior is shown in Figure 21, where the air-matte interface is displayed. Compared to the scaled-down furnace model, the flow pattern and even the flow details, including the bubble plume shape, seem to be the same in the full-scale model. Splashing and small bubbles are not discussed in this research study as these features were not included in the numerical model verification and would not influence the velocity distribution below the bath level. ${ }^{[17]}$

The velocity distribution of the full-scale furnace model is shown in Figure 22. It was found that, in all the investigated sections, the velocity distribution basically agreed with the scaled-down model described in subchapter 4.1.3, with only very small low velocity regions remaining. The relatively larger low velocity region near the side wall in Section I was found to be reduced by the rotation of bubble plumes, which means that this quiet situation would only happen periodically, rather than constantly. A further comparison is presented in Figure 23 , in which the variation in the dead zone volume fraction is illustrated. Except for a dramatic decrease before 4 seconds, which is obviously an unstable period, the dead zones in both the scaled-down and full-scale models shrank and were kept in a steady range with a volume fraction of below 0.06 . Therefore, in the full-scale model with a tuyere arrangement of $-16+0+16 \mathrm{deg}$, a comparatively smaller dead zone was also achieved, like that tested in the corresponding scaled-down model. Similarly, with the promotion of agitation behavior, the wall shear stress tends to expand into the side wall region, as shown in Figure 24. The wall shear stress in the side wall area does not exceed the level of the regions surrounding the tuyeres, which is regarded as the area under the strongest impact. This suggests that the furnace life span would not be significantly affected. 

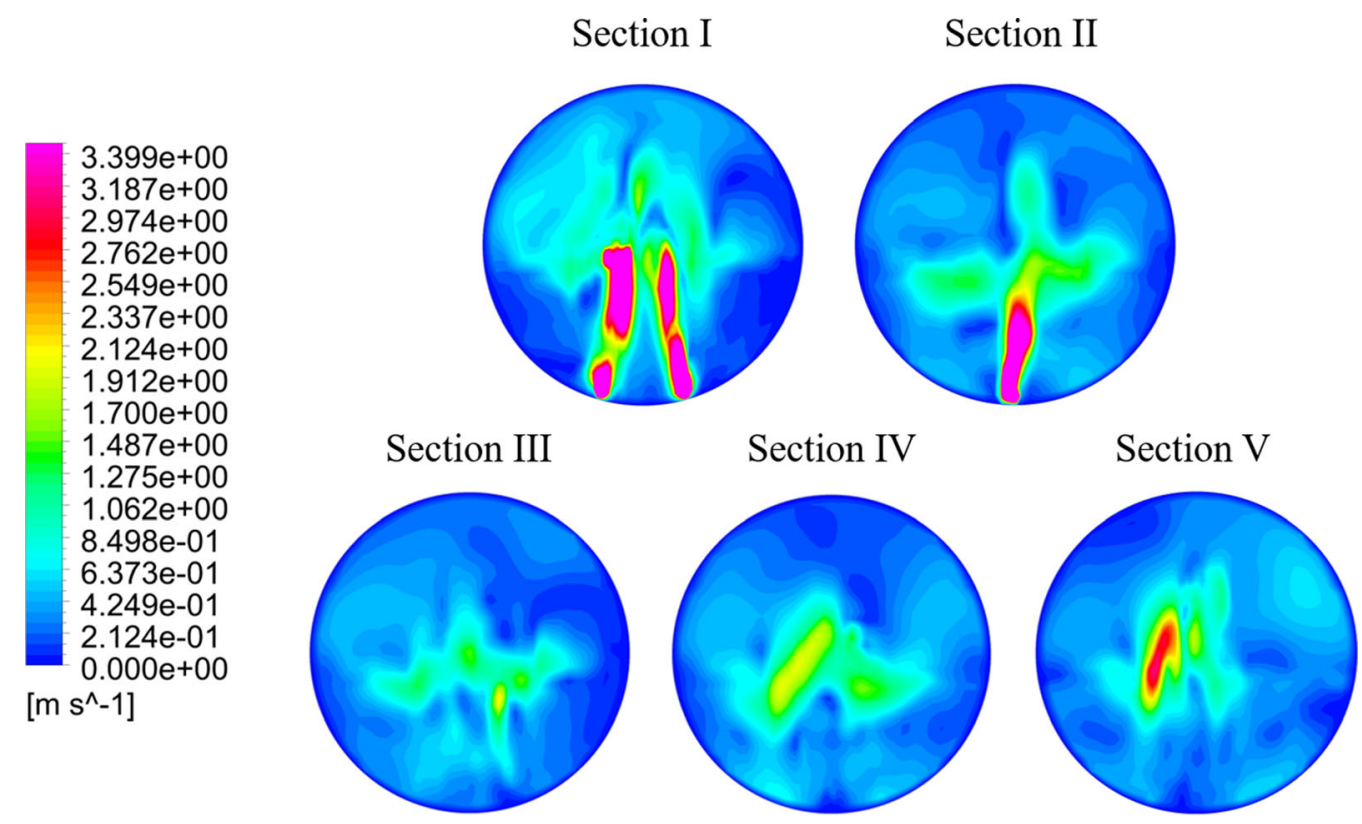

Fig. 22-Matte velocity distribution in Sections I-V of the simulated full-scale SKS furnace at $10 \mathrm{~s}$. Gas injection speed $=127.72 \mathrm{~m} \mathrm{~s}{ }^{-1}$, tuyere diameter $=48 \mathrm{~mm}$, pool depth $=1440 \mathrm{~mm}$. The range of the velocity legend is expanded based on the gas injection speed ratio of the full-scale and scaled-down furnace models.

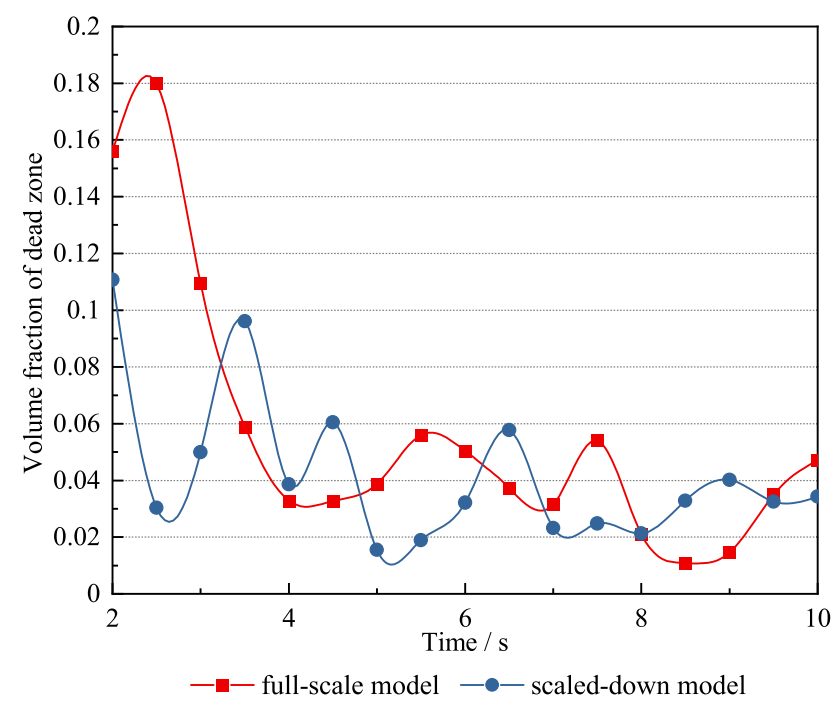

Fig. 23-Comparison of the dead zone volume fractions in the agitation zone of the full-scale and scaled-down models. Full-scale model: gas injection speed $=127.72 \mathrm{~m} \mathrm{~s}^{-1}$, tuyere diameter $=48$ $\mathrm{mm}$, pool depth $=1440 \mathrm{~mm}$. Scaled-down model: gas injection speed $=36.80 \mathrm{~m} \mathrm{~s}^{-1}$, tuyere diameter $=4 \mathrm{~mm}$, pool depth $=120$ $\mathrm{mm}$. The dead zone definition is based on the same proportion in the velocity range from the legends of Figures 16 and 22.

The test results concerning the full-scale model suggest that the $-16+0+16$ deg tuyere arrangement has the expected good performance in agitation efficiency and lining refractory protection. Unlike the elliptical furnace, the round furnace has already been in operation in industry for a long time and would not cause uncertainties in practice. As this arrangement has shown more potential than the other tuyere arrangements tested in this work, further investigation including a water model test and CFD test on other important parameters including pool depth, gas flow rate, and slag phase characteristics will be conducted in future.

\section{CONCLUSIONS}

In this work, new $-x+0+x$ deg tuyere arrangements are proposed. The agitation behavior and wall shear stress with different tuyere angles, gas injection speed, and furnace aspect ratios were tested at a constant total volumetric gas flow rate. Based on the results and comparison with the tuyere arrangement optimized in the previous work, the following conclusions have been drawn:

(1) For $-x+0+x$ deg tuyere arrangements, the mechanism of the flow field intensification achieved by using a larger tuyere angle or an elliptical furnace cross-section is the same, as both of the methods essentially enhance agitation by increasing the interactions between bubble plumes and the furnace wall.

(2) Using the $-x+0+x$ deg tuyere arrangements, the elliptical models show better performance with aspect ratios of 1.1:1 and 1.2:1, but may present challenges to the mechanical strength of the furnace.

(3) The $-x+0+x$ deg tuyere arrangements appear to create better agitation in the area between the tuyeres. A stronger agitation would be achieved if the injection speed were maintained at a high level by reducing the tuyere diameter.

(4) The tuyere arrangement of $-16+0+16$ deg merits further study, because it exhibits better agitation and relatively acceptable wall shear stress, and also 


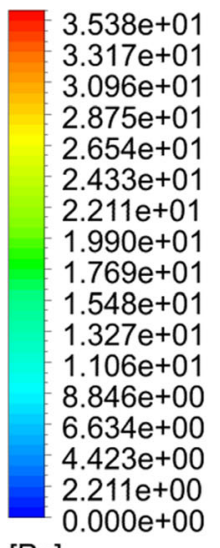

$[\mathrm{Pa}]$

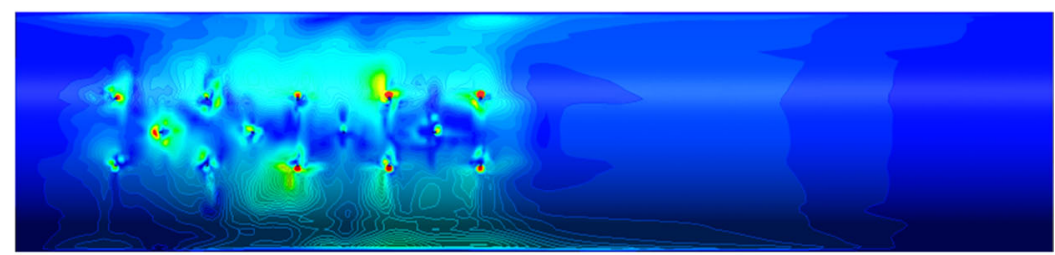

Fig. $24-$ Bottom view of the matte wall shear stress of the simulated full-scale SKS furnace at $10 \mathrm{~s}$. Gas injection speed $=127.72 \mathrm{~m} \mathrm{~s}^{-1}$, tuyere diameter $=48 \mathrm{~mm}$, pool depth $=1440 \mathrm{~mm}$. The range of the wall shear stress legend is expanded based on the gas injection speed ratio of the full-scale and scaled-down furnace models.

requires less modification to the furnace body. Furthermore, it has the least amount of dead zones.

\section{FUNDING}

Open access funding provided by Aalto University. This work was supported by the China Scholarship Council, and School of Chemical engineering, Aalto university.

\section{CONFLICT OF INTEREST}

On behalf of all of the authors, the corresponding author states that there is no conflict of interest.

\section{OPEN ACCESS}

This article is licensed under a Creative Commons Attribution 4.0 International License, which permits use, sharing, adaptation, distribution and reproduction in any medium or format, as long as you give appropriate credit to the original author(s) and the source, provide a link to the Creative Commons licence, and indicate if changes were made. The images or other third party material in this article are included in the article's Creative Commons licence, unless indicated otherwise in a credit line to the material. If material is not included in the article's Creative Commons licence and your intended use is not permitted by statutory regulation or exceeds the permitted use, you will need to obtain permission directly from the copyright holder. To view a copy of this licence, visit http://creativec ommons.org/licenses/by/4.0/.

\section{REFERENCES}

1. K. Song and A. Jokilaakso: Miner. Process. Extr. M., 2020, 1-15. 2. The World Copper Factbook. 2020, 35.
3. Z. Liu and L. Xia: Miner. Process. Extr. M., 2019, vol. 128 (1-2), pp. $117-24$.

4. G. Bressanelli, N. Saccani, D.C. Pigosso, and M. Perona: Sustain. Prod. Consum., 2020, vol. 23, pp. 174-88.

5. X. Wan, J. Fellman, A. Jokilaakso, L. Klemettinen, and M. Marjakoski: Metals, 2018, vol. 8(11), pp. 887.

6. S. Wang, W. Davenport, S. Yao, G. Walters, T. Gonzales, A. Siegmund and D. George: In: Proc. of Copper 2019, The Metallurgy and Materials Society of CIM, Canada, Vancouver, August $18-21,2019$

7. P. Coursol, P.J. Mackey, J.P.T. Kapusta, and N.C. Valencia: JOM, 2015, vol. 67 (5), pp. 1066-74.

8. D. Li, Z. Dong, X. Yao, C. Liu, T. Guo, B. Li, and P. Li: In 11th International Symposium on High-Temperature Metallurgical Processing, 2020, pp. 975-986. Springer, Cham.

9. Y. Yu, Z. Wen, X. Liu, G. Lou, F. Su, R. Dou, X. Hao, and Z. Lu: Nonferrous Met. (extractive metallurgy), 2013, vol. 4, pp. 12-16 In Chinese.

10. S. Qu, T. Li, Z. Dong, and H. Luan: Chin. Nonferrous Met., 2012, vol. 1, pp. 10-13 In Chinese.

11. L. Shui, Z. Cui, X. Ma, M.A. Rhamdhani, A. Nguyen, and B. Zhao: Metal. Mater. Trans. B, 2016, vol. 47, pp. 135-44.

12. L. Shui, Z. Cui, X. Ma, M.A. Rhamdhani, A. Nguye, and B. Zhao: Metal. Mater. Trans. B, 2015, vol. 46B, pp. 1218-25.

13. D. Wang, Y. Liu, Z. Zhang, T. Zhang, and X. Li: Can. Metall. Quart., 2017, vol. 56 (5), pp. 1-11.

14. H. Yan, F. Liu, Z. Zhang, Q. Gao, F. Liu, Z. Cui, and D. Shen: Chin. J. Nonferrous Met., 2012, vol. 22, pp. 2393-2400.

15. Z. Dong, D. Li, X. Yao, L. Min, B. Li, S. Liang, T. Guo, and Q. Xue: Nonferrous Met. Eq., 2019, vol. 2, pp. 36-41 In Chinese.

16. P. Shao and L. Jiang: Int. J. Mol. Sci., 2019, vol. 20, p. 5757.

17. K. Song and A. Jokilaakso: Metal Mater. Trans. B, 2021, vol. 52B (3), pp. $1772-88$

18. D.K. Chibwe, G. Akdogan, C. Aldrich, and P. Taskinen: Can. Metall. Quart., 2013, vol. 52 (2), pp. 176-89.

19. D.K. Chibwe, G. Akdogan, P. Taskinen, and J.J. Eksteen: J. S. Afr. I. Min. Metall., 2015, vol. 115 (5), pp. 363-74.

20. H. Zhang, C. Zhou, W. Bing, and Y. Chen: J. S. Afr. I. Min. Metall., 2015, vol. 115 (5), pp. 457-63.

21. W. Liu, H. Tang, S. Yang, M. Wang, J. Li, Q. Liu, and J. Liu: Metal. Mater. Trans. B, 2018, vol. 49B (5), pp. 2681-91.

22. ANSYS Fluent Theory Guide 19.0, 2018, pp. 505-10.

23. ANSYS Fluent Meshing User's Guide 17.0, 2016, p. 313.

24. MAERZ, Copper Recycling Conference, Brussels, June 2012.

25. Z. Cui, D. Shen, Z. Wang, W. Li, and R. Bian: Nonferrous Met. (extractive metallurgy), 2010, vol. 03, pp. 17-20 In Chinese.

Publisher's Note Springer Nature remains neutral with regard to jurisdictional claims in published maps and institutional affiliations. 